\title{
The diversity and distribution of endophytes across biomes, plant phylogeny, and host tissues - how far have we come and where do we go from here?
}

\author{
Joshua G. Harrison ${ }^{1}$, Eric A. Griffin ${ }^{2}$ \\ ${ }^{1}$ Department of Botany, University of Wyoming, Laramie, WY 82071, USA \\ 2 New Mexico Highlands University, Las Vegas, NM 87701, USA
}

Corresponding author: Joshua G. Harrison

1000 E. University Ave.

Department of Botany, 3165

University of Wyoming

Laramie, WY 82071, USA

joshua.harrison@uwyo.edu

Keywords: endophytes, fungal endophytes, bacterial endophytes, phyllosphere, microbial ecology, biodiversity, biogeography, plant-microbe interactions

Running title: Endophyte diversity and distribution

Author contributions: JGH and EAG conducted the literature survey and wrote the manuscript. 


\section{Originality-Significance Statement}

Much remains to be learned regarding the biodiversity and distribution of the microbes that colonize the interiors of plants. Here, we surveyed approximately 600 publications to characterize gaps in knowledge and provide a roadmap for future research. We compared biomes, plant families, and geographical regions in terms of the research interest that they have garnered. Additionally, we synthesized published results and report that variation in endophyte richness among plant tissue types is a function of host growth habit. Stems were the richest tissue in woody plants, whereas roots were the richest tissue in graminoids. We hope to inspire research to fill the gaps in knowledge that we uncovered.

\section{Abstract}

The interiors of plants are colonized by diverse microorganisms that are referred to as endophytes. Endophytes have received much attention over the past few decades, yet many questions remain unanswered regarding patterns in their biodiversity at local to global scales. To characterize research effort to date, we synthesized results from $\sim 600$ published studies. Our survey revealed a global research interest and highlighted several gaps in knowledge. For instance, of the seventeen biomes encompassed by our survey, seven were understudied and together composed only $7 \%$ of the studies that we considered. We found that fungal endophyte diversity has been characterized in at least one host from $30 \%$ of embryophyte families, while bacterial endophytes have been surveyed in hosts from only $10.5 \%$ of families. We complimented our survey with a vote counting procedure to determine endophyte richness patterns among plant tissue types. We found that variation in endophyte assemblages in above-ground tissues varied with host growth habit. Stems were the richest tissue in woody plants, whereas roots were the richest tissue in graminoids. For forbs, we found no consistent differences in relative tissue richness among studies. We propose future directions to fill the gaps in knowledge we uncovered and inspire further research.

\section{Introduction}

In 1887, Galippe reported that soil-derived microbes could reside within the above-ground tissues of healthy plants. At the time, this work was underappreciated, perhaps because of the long-prevailing attitude that microbial assemblages solely comprised deleterious pathogens (Compant et al. 2012), this notwithstanding the work of A. B. Frank and others demonstrating the mutualistic nature of the mycorrhizal-host relationship (Frank 1885. Frank 2005, Trappe 2005). Nevertheless, Galippe's observations set the stage for an exploration of the non-pathogenic portion of the plant microbiome that took place from the late 1800s into the mid 1900s (Auret 1930; Hardoim et al. 2015; Janse 1897; Laurent 1889, Rayner 1915). During those decades, knowledge began to accumulate regarding the diversity, prevalence, and ecological roles of so called "endophytes" (Box 1; Campbell 1908, Hyde and Soytong 2008), with much early work focused on the fungi living within grasses (e.g., Neill 1940, Sampson 1937). Seminal research in the 1970 s and 80s led to widespread acknowledgement of the 
ubiquitous nature of non-pathogenic fungi and bacteria in plant tissues, particularly within leaves (Carroll and Carroll 1978; Carroll 1988, Petrini 1991). These studies have inspired an ever-growing interest from microbial ecologists (Fig. 1), yet answers to many basic questions regarding the natural history, biogeography, ecology, and evolution of endophytes remain elusive.

What is clear, however, is that fungal and bacterial endophytes are important-even critical - components of the world's ecosystems. Endophytes can affect plant phenotype, including decreasing disease susceptibility (Arnold et al. 2003 Busby et al. 2016; Christian et al. 2017; Compant et al. 2005; Herre et al. 2007), increasing resistance to abiotic stressors (Márquez et al. 2007; Redman et al. 2002 Rodriguez et al. 2008), shaping phytochemical profiles (Kusari et al. 2012 Panaccione et al. 2014), and mediating plant functional trait expression (Griffin et al. 2016, Friesen et al. 2011). Recent work has demonstrated how these various effects of endophytes can influence whole ecosystem level processes (Christian et al. 2019; Clay and Holah 1999; Griffin et al. 2017; Kivlin et al. 2013 Laforest-Lapointe et al. 2017b). Importantly, endophytes are often erroneously assumed to have predominantly mutualistic associations with their hosts. Reality is much more complex and the influence of endophyte taxa is highly context dependent (Carroll 1988; Rodriguez et al. 2009), with interactions between hosts and endophytes ranging from mutualism through commensalism to latent or mild antagonism (Hardoim et al. 2008; Schulz and Boyle 2005; Saikkonen et al. 1998).

Much of the focus on endophytes has been driven by applied scientists interested in harnessing these taxa as a means to manipulate plant phenotype (e.g., increase growth; Doty 2011) and prevent pathogen colonization of crops (Busby et al.2017). Endophytes have also attracted attention from natural products chemists who survey the world's organisms for useful compounds (Aly et al. 2010; Strobel and Daisy 2003). This is motivated by the capacity of various endophytes to synthesize an impressive array of bio-active small molecules (Newman et al. 2003; Strobel et al. 2004, Verma et al. 2009). Indeed, a number of endophytesynthesized compounds are of medicinal value (Kharwar et al. 2011; Strobel et al. 1996).

Both basic and applied research regarding endophytes have been hampered by a lack of knowledge regarding the distribution of endophyte biodiversity at any spatial scale - from global, inter-biome scales to among the tissues of individual host plants. Similarly, almost nothing is known regarding how endophyte biodiversity maps onto the plant phylogeny. Characterizing such broad patterns in endophyte biodiversity is extremely logistically challenging because of the outlay of effort required for large culturing and sequencing projects (Arnold and Engelbrecht 2007; Carini 2019; Nilsson et al. 2018). Moreover, determining the causes of patterns in endophyte diversity is difficult because they result from the interplay of many forcings, including both contemporary and historical ecological drivers (i.e., niche determination, ecological drift, dispersal limitation) and, at longer timescales, evolutionary processes (i.e., divergence and extinction; Hanson et al. 2012 Wiens and Donoghue 2004).

Further complicating matters is the disconnection between the spatial scale of sampling endophyte assemblages, as dictated by logistical constraints, and the size of the focal organisms. This problem was well illustrated by Remus-Emsermann and Schlechter (2018) who point out that the disparity in size between a single bacterium of $2 \mathrm{\mu m}^{3}$ and a leaf mirrors the ratio of sizes between a person and a mid-sized country. Indeed, using traditional culturing 
and sequencing methodologies, we can only sample what are in effect whole regions of endophytes that may include multiple assemblages that never directly interact, that have been shaped by differing community assembly processes, and that may even have divergent evolutionary histories. This complicates the study of endophyte biogeography and community ecology because the scale of sampling is so much larger than many covariates that may affect membership of endophytes in a particular assemblage. For instance, microhabitat variation within leaves (such as proximity to upper or lower leaf surfaces, veins, etc.) may have effects on endophyte assemblages akin to those of shifting elevation across a mountainside on forest composition, and those forcings are unavailable for study when the unit of replication is an entire leaf, or even a leaf section (Herre et al. 2007; Lodge et al. 1996; Remus-Emsermann and Schlechter 2018, Vacher et al. 2016). Adding further complexity, some bacterial endophytes can live inside endophytic fungi (Shaffer et al. 2016); thus, for these bacteria, the habitat covariates most relevant for explaining inter-assemblage variation may be the traits of the host fungus, not the traits of the host plant.

While we have much to learn regarding the distribution of endophyte biodiversity, patterns observed so far generally follow the predictions of community ecology theory and are similar to those observed for metazoan and plant assemblages (Christian et al. 2015. Nemergut et al. 2013). For instance, sampling of endophyte assemblages recapitulates the positive species-area relationship observed in so many natural systems - as one samples a larger area one encounters more taxa (e.g., Suryanarayanan et al. 2002). A necessary correlate of this observation is that the similarity among endophyte assemblages declines with distance, which also has been demonstrated numerous times (e.g., Davis and Shaw 2008 Higgins et al. 2014 Nemergut et al. 2013 Vacher et al. 2016). While its causes are multifarious and poorly understood (Martiny et al. 2006 Vellend 2010), the existence of distance-decay suggests that endophytic microbes are influenced not only by deterministic forcings, but also by what are typically regarded as neutral processes, such as dispersal limitation and ecological drift (Hubbell 2001; MacArthur and Wilson 2001; Nemergut et al. 2013). Also following what is known for most large, multi-cellular organisms, foliar fungal endophyte biodiversity seems to follow a latitudinal gradient, with higher diversity at lower latitudes, as shown by Arnold and Lutzoni (2007). The reasons for this pattern remain unknown, but likely include both contemporary and historical drivers (Mittelbach et al. 2007; Pianka 1966). Importantly, it is unclear if this pattern holds for non-fungal taxa and if non-foliar tissues harbor higher fungal endophyte richness at lower latitudes. Indeed, ectomycorrhizal fungi appear to be at their richest in temperate zones (Tedersoo et al. 2014), which suggests the possibility that other root associated microbes may be richest at intermediate latitudes as well.

Much of what is known regarding patterns of endophyte biodiversity demonstrates the influence of contemporary ecological contingencies at either regional or local spatial scales (i.e., niche determinism). For instance, Zimmerman and Vitousek (2012) reported greater fungal endophyte richness at wetter, low elevation sites on a Hawaiian mountainside and Bowman and Arnold (2018) found that Pinus ponderosa hosted more diverse foliar fungal endophyte communities at mid-to-high elevations compared to lower elevations in southwestern Arizona (also see Giauque and Hawkes 2013; Glynou et al. 2016; Lau et al. 2013). Furthermore, it is clear that endophyte assemblages shift among coexisting host species, 
though the effect of host on endophyte assemblage divergence can be quite modest in some cases (Griffin et al. 2019, Redford et al. 2010; Vincent et al. 2015). While evidence reported to date suggests that many cultivable endophytes are host generalists (e.g., Arnold and Lutzoni 2007; Suryanarayanan 2018), specialist endophytes do exist, as demonstrated by the fidelity of vertically-transmitted (seed borne) Epichloë fungi to members of Poaceae (Clay and Schardl 2002 Rudgers et al. 2009) and of swainsonine-producing Alternaria fungi to certain Fabaceous taxa (Cook et al. 2014 Panaccione et al. 2014). However, the host range of the myriad endophytes that occur at low relative abundances is unknown (Arnold and Lutzoni 2007) - an important gap in knowledge given that these taxa likely comprise the bulk of endophyte biodiversity (Arnold and Lutzoni 2007; Lynch and Neufeld 2015).

Even within an individual plant, niche determinism can shape endophyte assemblages as many studies have confirmed that endophyte assemblages vary among tissue types (e.g., the endophyte assemblages in roots often differ from those in leaves; e.g., Coleman-Derr et al. 2016; but see Haruna et al. 2018; Massoni et al. 2019), though general patterns in endophyte richness among tissue types have not been described.

Niche determinism is not the only force affecting endophyte biodiversity within a particular substrate, though it is likely the best studied. For instance, it is clear from research within non-endophytic taxa that microbes can be dispersal limited and therefore the longstanding Baas Becking hypothesis for microbial biogeography, namely that "everything is everywhere, but the environment selects" (Baas Becking 1934) is too simplistic (Hanson et al. 2012 Martiny et al. 2006 Nemergut et al. 2013; Vellend 2010). It is still unclear, however, how dispersal limitation and ecological drift (stochastic changes in community membership due to aggregated life history events) shape endophyte community assembly. Similarly, little is understood regarding the influence of historical factors, including divergence and extinction, on endophyte biogeography, though it seems likely that these factors will manifest in differences in endophyte assemblages across biomes and geographical regions, just as they do for other taxa (Mittelbach et al. 2007). How often these forces act at what are, to our sensibilities, small spatial scales, such as within a forest or even a single-long-lived tree, remains unknown.

A final challenge to the study of endophyte distribution is the likelihood that most patterns in biodiversity will be taxon specific, because taxa respond differently to ecological contingencies and are on varying evolutionary trajectories. For example, Coleman-Derr et al. (2016) suggest that prokaryote taxa are more influenced by plant tissue type than fungal taxa, which are affected more by host habitat and biogeography. At the order level, Jumpponen et al. (2017) suggested that Helotiales fungal root endophytes are most abundant in forested ecosystems and Pleosporales fungi are more common in grasslands. Studies such as these are very rare; very little is known regarding the geographical or host ranges of endophytes at any level of the biological hierarchy - from phylum to subspecies.

While daunting, the study of endophyte biogeography and community assembly will likely provide important benefits for both basic and applied research. An exemplar is provided by Higginbotham et al. (2013) who isolated over 3000 endophytic fungi from numerous tropical angiosperms and ferns and tested these cultures against common diseases, including malaria, Chagas disease, and cancer. They report that $30 \%$ of the fungi showed strong activity against at least one of the focal diseases and that bioactivity against a specific target was 
non-randomly distributed across the fungal phylogeny. Intriguingly, they also reported a generally higher degree of bioactivity in taxa sourced from cloud forests compared to lowland tropical forests - thus providing a biogeographic road-map for natural product discovery in tropical forests that demonstrates an important role of both biome and host phylogeny (also see Schulz et al. 2002).

The first step towards a working knowledge of endophyte distributions across spatial scales is the description of broad patterns in their biodiversity. To understand the scope of relevant research, we scoured the literature and extracted basic metadata from 596 studies characterizing endophyte assemblages. Our goal was to synthesize the meta-data from representative studies, with the hopes of highlighting particular portions of the plant phylogeny and specific biomes that need further exploration and to determine how information could be shared among studies. Additionally, we paired our survey with a vote counting procedure where we compared patterns of endophyte richness among tissue types. The synthesis process illustrated the challenges of pooling information among studies and, consequently, we offer specific guidelines for data sharing and research reproducibility moving forward. For our purposes in this article, we did not consider obligate pathogens, epiphytes, or mycorrhizae; nor did we include a review of the large body of literature examining Rhizobia and their associations with legumes, as others have already done so (e.g., Peter et al. 1996 . Willems 2006). 


\section{Box 1. What, exactly, is an endophyte?}

The term 'endophyte' is believed to have originated with de Bary (1866), who so dubbed pathogenic, plant-inhabiting microbes, because of their habitat (also see Link 1809). Since then, the term endophyte has been expanded to invoke both a habitat and a non-pathogenic lifestyle (at least in some hosts and life history stages), and encompasses fungal (Rodriguez et al. 2009, Petrini 1991), bacterial (Griffin and Carson 2015 Ryan et al. 2008), and archael taxa (Moissl-Eichinger et al. 2018; Müller et al. 2015). The term endophyte can be used sensu lato to refer to those taxa that live inside of plant tissues, either inside of or between host cells. However, in our experience, contemporary microbial ecologists most often use the term sensu stricto to refer to those taxa which over some portion of their life history, do not cause obvious harm to their hosts, such as inducing a hypersensitive response (Wilson 1995, Petrini 1991, Stone et al. 2000). The lack of precision in this definition is somewhat unsatisfying, but does hint at the complex life histories of many endophytic taxa (Rodriguez et al. 2009). Indeed, for perhaps the majority of endophytic taxa, individuals are horizontally transmitted among hosts and, consequently, may exist outside of the plant corpus for some time, for instance as spores or endospores, free living cells or colonies, or as epiphytic fruiting bodies on decaying tissue (Malloch and Blackwell 1992 Rodriguez et al. 2009). The term endophyte is particularly strained by the mycorrhizal fungi, which possess a mycelium that grows externally to the host but that also penetrates the root epidermis (Schulz and Boyle 2006; Jumpponen 2001). The categorization of these fungi as endophytes seems to be on an author-by-author basis (Schulz and Boyle 2006). These examples illustrate how the term endophyte is useful for communication, but not biologically well-delineated.

\section{Methods}

We searched Google Scholar and Web of Science for the term "endophyte" in conjunction with "fungal", "bacterial", "diversity", or "community". All publications in which the authors characterized endophyte assemblage biodiversity were collated. As we were primarily interested in studies characterizing endophyte biodiversity, we did not consider research involving manipulative experiments where no survey of microbial diversity was conducted. We also made the choice to omit studies that did not distinguish between epiphytes and endophytes through performing some form of surface sterilization. Searches were performed periodically from 2016-2018 and additional studies added to our database as we became aware of them until the beginning of 2019. We apologize to those authors whose work we missed and to those who have published their work in non-English language journals, which typically did not appear in our searches and were inaccessible to us because of our linguistic backgrounds.

From each study, we collected information on host organism(s) studied, research location(s), tissue type(s) surveyed, and various metadata describing the nature of the survey 
conducted - for instance, if the endophyte assemblage was characterized via sequencing or culturing, if spatial or temporal replication was employed, host and culture vouchers deposited, and data made available. We considered studies spatially replicated if they involved two or more sampling locations separated by $\geq 1 \mathrm{~km}$. We chose this threshold because of work by Higgins et al. (2014) who reported rapid distance-decay in endophyte assemblage similarity within tropical grasses within $1 \mathrm{~km}$. It is likely that the strength of distance-decay depends upon biome, host plant, endophyte taxon, and other ecological conditions, thus determining what constitutes sufficient spatial replication is challenging and study-dependent. We use a $1 \mathrm{~km}$ threshold here because most studies that were replicated at a smaller spatial scale were within a single field, forest, or greenhouse and thus were likely exposed to similar endophyte inoculum, at least over longer timescales. If the study location was not explicitly provided, we extrapolated an estimate based on the city or country reported by the authors. We assigned studies to biomes following the nomenclature of Olson et al. (2001). Host plants collected from urban, agricultural, or areas that were otherwise managed, were classified as coming from "cultivated" landscapes and counted independently from those studies that occurred in unmanaged landscapes within the same biome. We chose this approach because managed areas experience ecological contingencies divergent from their surroundings (e.g., irrigation). We considered studies of "stems" as those involving sampling of woody branches, twigs, or grass shoots. Studies of "roots" included any survey of below-ground plant tissue, but excluded rhizosphere soil surveys and studies which did not attempt to surface sterilize roots. We considered studies of "leaves" to be those sampling leaf sections or whole leaves/leaflets (including needles) and did not consider studies that combined petioles with leaf blade tissue.

To understand the phylogenetic breadth of host plants surveyed, we calculated the total number of hosts examined for each plant family and plotted this information on a phylogeny of the Embryophyta (algal endophyte hosts were thus omitted from this portion of our analysis) generated using phyloT (online software accessible at https://phylot.biobyte. de/). The National Center for Biotechnology Information taxonomy database was used to generate the tree (database accessed March 15, 2019; Federhen 2012). iTOL v4.3.2 was used for tree visualization (Letunic and Bork 2016). All data manipulation was performed in the $\mathrm{R}$ statistical computing environment ( $\mathrm{R}$ Core Team 2019).

Vote counting to determine patterns in relative tissue richness

In addition, we asked how endophyte richness shifted among tissue types, for both fungi and bacteria. We attempted two approaches to address this question - a formal meta-analysis and a simple vote counting approach. Because few studies used the same methods, comparing the effect of tissue type on richness among studies was inappropriate (this limitation also precluded comparison of richness among taxa or across biomes, unfortunately). Thus, we only examined those studies that compared richness among multiple tissue types and all comparisons were made within studies.

Unfortunately, very few studies provided data sufficient for a quantitatively rigorous meta-analysis (see Supplemental Methods and Results), so we conducted a simple vote counting procedure where we considered each study independently and ranked tissue types by the relative richness reported in that study. We only considered those studies that examined multiple tissues and that standardized sampling effort among tissues. In total, we examined 
243 studies: 182 studies of fungal endophytes and 61 studies of bacterial endophytes. After ranking tissues by relative richness separately for each study, we calculated, across studies, the proportion of times one tissue type had higher richness than another tissue (e.g., for what proportion of studies did leaves have higher richness than roots) and calculated the probabilities of these proportions using a binomial sign test (Cooper and Hedges 1993). This test is simply the probability of observing a particular number, or more, of positive outcomes (in our case, one tissue type having higher richness than another) given a certain number of trials and assuming equal probability of positive and negative outcomes. For this vote counting approach, we focused on richness because fewer studies reported diversity metrics and, when not explicitly reported by authors, relative richness was simpler to calculate and extract from published summary tables and figures than were diversity entropies. To test how growth habit influenced relative microbial richness among tissues, we conducted vote counting separately for studies of hosts with the following growth habits: woody-stemmed trees and shrubs, forbs, and graminoids.

\section{Results}

Our survey highlighted the breadth of the endophyte biodiversity literature, as we extracted data from 596 unique publications. We report that interest in endophyte diversity is on the rise, with a sharp increase in studies per year since 2010 (Fig. 1). Fungi have received comparatively more attention than bacteria, though this disparity is diminishing (Figs. 1 \& 2 2e). The majority of studies were of foliar endophytes (1694 unique combinations of study and host species), followed by root (577 combinations) and stem (540 combinations) endophytes. By comparison, floral tissues (39 combinations) and plant propagules were understudied (172 combinations; Fig. 2). Multiple-host studies were not the norm - approximately $\sim 66 \%$ of studies focused on a single host taxon.

\section{The global extent of endophyte biodiversity research}

The geographical range encompassed by the studies we considered was global; endophytes, both fungal and bacterial, have been recovered from hosts across all major biomes (Fig. 3). Temperate mixed coniferous and deciduous forests were the best studied, with 98 studies (16\% of total). However, the most unique combinations of host and study were reported from tropical and subtropical wet forests $(471,21 \%$ of total). This was due to several studies that surveyed many hosts within these forests (e.g., Rojas-Jimenez et al. 2016 with 92 hosts and Suryanarayanan et al. 2011 with 70 hosts). In terms of unique studies, research in tropical and subtropical forests composed a more modest $13 \%$ of studies in our survey. Many biomes were quite understudied. For instance, 50 or fewer studies (in terms of unique host by study combinations) were conducted in seven of the seventeen biomes that we considered (Fig. $2 \mathrm{~b}$ ). Together, studies from these biomes composed only $7 \%$ of those surveyed.

Across biomes, we found comparatively few studies of hosts growing in obvious wilderness, far from human development. Indeed, $33 \%$ of studies relied on hosts grown in cultivated environments, including urban locations, agricultural landscapes, and greenhouses (with university campuses being particularly well sampled). This estimate may be conservative as for some studies the exact collection location was difficult to determine and so we did 
not include them in the "cultivated" category, but sampling was likely not far from human development.

\section{Much of the host phylogeny remains unsampled}

The studies we surveyed encompassed 1702 unique taxa from 254 plant families. Poaceae was by far the most well-studied family (189 hosts studied), followed by Fabaceae (98 hosts), Pinaceae ( 82 hosts), and Asteraceae (79 hosts; Fig. 44). In the studies we examined, fungal endophytes have been surveyed in hosts from $30 \%$ of plant families listed in the NCBI taxonomy database for Embryophyta. By comparison, bacterial endophytes have been characterized in only $10.5 \%$ of plant families. Of particular note, very few observations of foliar microbiota have been made among bryophyte and pteridophyte families (Fig. 44 Davis and Shaw 2008 Desirò Alessandro et al. 2013). Additionally, we observed a mismatch between host family species richness and sampling effort. For instance, only 29 Orchidaceae species have been surveyed out of the approximately 28,000 accepted orchid taxa occurring worldwide (The Plant List, Chase et al. 2015).

\section{Replication and reproducibility could be improved}

We also characterized details for each study regarding sampling scheme and reproducibility (Fig. 2 $2 \mathrm{de}$ ). We found that just over half of studies were spatially replicated (sampling areas were separated by at least a $\mathrm{km}$ ) and fewer than a quarter of studies were temporally replicated. The majority of studies ( $74 \%)$ relied on culturing, however only about a third of these studies reported accessioning cultures (Fig. 2). By comparison, $72 \%$ of studies that relied on sequence data provided clear instructions for downloading raw data, though only $23 \%$ of these studies provided processed data (such as an OTU table). Surprisingly, fewer than $20 \%$ of studies mentioned accessioning host vouchers. For cultivated plants, we considered a description of the cultivar as equivalent to an accessioned voucher.

The effects of tissue type on endophyte richness and diversity

We performed vote counting to compare the relative richness and diversity of fungal endophyte assemblages in varying tissue types across plant taxa. We resorted to vote-counting because data were insufficient for a robust meta-analysis (see Supplemental Methods and Results). We found that relative tissue richness was dependent upon host growth habit. For instance, stems had richer fungal endophyte assemblages than leaves for woody-stemmed hosts, but this pattern was not observed for either forbs or graminoids (Table S1). By comparison, for graminoids, roots had richer fungal and bacterial endophyte assemblages than stems (Table S3). For forbs, no tissue type was clearly richer, on average, than other tissues (Table S2). Additionally, for fungal endophytes, we found that reproductive structures, including flowers and propagules, were relatively species poor, while bark was species rich (Table S1 \& S2), though these results are quite tentative given the few studies that compared endophyte assemblages in these tissues to those in other portions of the plant corpus.

\section{Discussion}

We report that endophyte biodiversity has been studied within all major biomes and continents (even Antarctica, if one counts King George Island; Fig. 3, Rosa et al. 2009). Given that widespread interest in endophytes did not occur until the 1970s, progress has been 
rapid. However, great swathes of the globe still remain unsurveyed. Certain biomes have been particularly understudied - either due to their high biodiversity, which makes thorough sampling exceptionally difficult (i.e., tropical rainforests); large geographical area (e.g., the boreal forest); or because they are geographically restricted and simply have not received much attention. For instance, we found few studies from coastal dunes, flooded grasslands, and mangrove forests. These habitats are challenging for plants, due to salinity, short intervals between disturbances, and the presence of anoxic soil. Surveys of understudied biomes will help define the scope of endophyte biodiversity and functional traits. In particular, we suggest that surveys in flooded grasslands and mangroves may improve our understanding of archael endophyte biodiversity (Moissl-Eichinger et al. 2018), as this branch of life includes numerous halophiles and other extremophiles that may be able to cope with the abiotic conditions characteristic of those locations. Similarly, studies in desert and alpine biomes may uncover endophytes with unique mechanisms for coping with the severe ultraviolet exposure, temperature swings, and desiccation that occurs in such harsh habitats (see for example, Lopez et al. 2011; Massimo et al. 2015; Sangamesh et al. 2017).

We also reported a lack of studies from Africa, west and north Asia, and the interiors of Australia and South America (Fig. 33). These areas hold some of the most biodiverse and charismatic landscapes on the planet; for instance, the Congo basin is the second largest tropical rainforest in the world, with thousands of endemic plant taxa (Brenan 1978; Linder 2001), and it has historically experienced less deforestation than other rainforests (Koenig 2008). Similarly, the Cape Floristic province in Africa has some of the highest levels of plant endemism in the world. Because these regions have evolutionary histories that have facilitated endemism, it seems likely that they harbor unique endophyte taxa and would be prime locations to study coevolution and codivergence between plants and endophytes. More generally, the lack of sampling outside of North American, Europe, and portions of Asia precludes a robust knowledge of endophyte biogeography.

\section{The influence of human development on endophyte biodiversity}

We acknowledge the logistical challenges of sampling the remote locations that remain understudied. Indeed, we report an imprint of this challenge in even relatively well-studied regions, where we found that most studies were conducted near roadways, townships, and other human development. The lack of sampling in wilderness areas likely biases our nascent understanding of endophyte biodiversity. Human development is associated with pollution, habitat fragmentation, ecosystem disturbance frequency, and the abundance of introduced hosts (Crowl et al. 2008, Dietz et al. 2007) - all of which likely affect plant microbiomes. Evidence for this hypothesis is sparse, however Laforest-Lapointe et al. (2017a) reported many phyllosphere bacterial taxa shift in relative abundance along an urbanization gradient, with an overall decline in dominant Alphaproteobacteria with more urbanization. Similarly, Lappalainen et al. (1999) reported a decline in endophyte colonization of Betula trees with proximity to a copper-nickel smelter. Variation in heavy metal concentrations (Tóth et al. 2009 Jurc et al. 1996), acid rain (Helander et al. 1994), and air pollution (Wolfe et al. 2018), have all been associated with shifts in endophyte assemblages - thus, it seems likely that the effects of pollution and urbanization are multifarious and have effects which depend upon the endophytic taxon examined and the ecological context.

In addition to pollution, habitat fragmentation also increases in proximity to human 
development. Very little is known regarding how habitat fragmentation affects microbial assemblages or, more generally, how metacommunity processes manifest within microbiomes (Christian et al. 2015). However, classic island biogeography theory (MacArthur and Wilson 2001) suggests that human-caused habitat fragmentation likely shapes endophyte assemblages through determining proximity to inoculum sources. In a survey spanning islands of various sizes, Helander et al. (2007) reported that endophyte colonization of Betula spp. trees was greater on larger islands and islands closer to the mainland (also see Oono et al. 2017). This result, coupled with work documenting dispersal limitation in non-endophyte, microbial systems (Golan and Pringle 2017; Peay et al. 2010; Peay et al. 2007; Andrews et al. 1987) suggests that it is reasonable to expect variation in endophyte assemblages routinely follows the predictions of island biogeography, regardless of whether habitat fragmentation and patch size is caused by geological processes or human influence.

Another way in which endophyte assemblages may be affected by proximity to human development is through the influence of invasive plant taxa, which are often much more abundant near development than in wilderness areas. Invasive host taxa could influence endophytes in a variety of ways - from changing the inoculum pool within an area (i.e. "neighborhood" effects; Moeller et al. 2015), bringing along endophyte taxa or genotypes from the ancestral range of the host (Dickie et al.2017), or affecting many other aspects of the local ecology (e.g. shifting fire regimes [Brooks et al. 2004], determining litter deposition rate and elemental composition [Allison and Vitousek 2004], influencing herbivore assemblages [Forister 2009], etc.).

Interestingly, the few studies we encountered that surveyed endophytic microbiomes of invasive plants in both their native and invaded ranges found that endophyte assemblages differed between ranges. For instance, Lu-Irving et al. (2019) report reduced richness in phyllosphere and endophytic root bacteria in the invaded portion of the range of Centaurea solstitialis compared to the native range. Similarly, Shipunov et al. (2008) report a wholesale shift in the fungal endophyte assemblage within the leaves of Centaurea stoebe in invaded versus native portions of its range. Thus, the biodiversity of endophytes within widespread, invasive plants is also influenced by host invasion history (also see Gundale et al. 2016; Sikes et al. 2016; Taylor et al. 1999).

All of these anecdotes support the idea that endophyte assemblages in relatively undisturbed areas, such as portions of the Amazon or the Siberian forest, are likely to be different from those in conspecific hosts growing near human habitation or that are being actively cultivated and thus remote locations should be the focus of further study. Even if different microbial taxa are not observed in less disturbed environments, study of the shifts in relative abundances among endophyte assemblages along urbanization and pollution gradients could provide insight into how endophytes interact and communities assemble (e.g., Gazis and Chaverri 2015).

Much of the host phylogeny remains unexplored - what might we be missing?

We found that members of about a third of plant families have been surveyed for fungal endophytes and only about a tenth of plant families are represented among studies characterizing bacterial endophyte assemblages. These results suggest we may be missing a large portion of endophyte biodiversity. It is true that many cultivable endophytic taxa are known to have broad host ranges (e.g., Arnold and Lutzoni 2007; Suryanarayanan 2018), thus one 
could argue that an understanding of endophyte biodiversity does not hinge on thorough sampling of potential host taxa. However, we note that, in the majority of multivariate studies of endophyte biogeography, host taxon is an important predictor of assemblage variation (Griffin et al. 2019 Kivlin et al. 2019) - albeit a sometimes modest one (Vincent et al. 2015). Moreover, little is known regarding the host range of those rare endophyte taxa that compose the bulk of most assemblages (Arnold and Lutzoni 2007).

Studies delineating host range are desperately needed to understand endophyte distributions and biodiversity, however given the daunting nature of the sampling required, where then should we begin? We suggest targeting those plant lineages with unique traits, such as production of unusual secondary metabolites or preferences for restricted or harsh habitats (e.g. halophiles and extremophiles). As an example, certain Astragalus taxa can hyperaccumulate selenium, and recent research has suggested that these plants may harbor unusual endophytic taxa that could influence selenium uptake (Sura-de Jong et al. 2015; Lindblom et al. 2018, Lindblom et al. 2013). Following a similar rationale, we also suggest surveying those plant families that are phylogenetically distinctive. If coevolution or codivergence has occurred between hosts and their endophytes, then unusual endophytic taxa could occur in hosts from remote portions of the plant phylogeny (Hassani et al. 2019). Non-vascular plants, in particular, deserve more attention, as these plants have different evolutionary histories, physiology, growth habits, and preferred habitats than vascular plants (Huang et al. 2018).

An additional justification for surveying broadly across the plant phylogeny is the discovery of specialist endophyte taxa. Surveys of seeds, in particular, could lead to the discovery of more vertically-transmitted endophytes (class I and II endophytes sensu Rodriguez et al. 2009), which are particularly interesting because of their capacity to influence their hosts during early ontogeny (e.g., Gundel et al. 2017; Hodgson et al. 2014; Truyens et al. 2015). An individual seed generally contains a very species poor endophyte assemblage (e.g., in many cases only a single fungus was isolated from seeds, see Hodgson et al. 2014; Newcombe et al. 2018 Shipunov et al. 2008), and relatively few instances of vertical transmission of endophyte taxa have been documented. However, recent work by Hodgson et al. (2014) provides evidence that vertical-transmission of fungi may occur much more often than previously suspected (also see a review on bacterial seed endophytes by Truyens et al. 2015). Indeed, while the well-known clavicipitaceous endophytes seem to be limited to members of the Poaceae (Rudgers et al. 2009), the occurrence of vertically-transmitted endophytes capable of systemic growth has been documented from throughout the plant phylogeny, including within members of the Asteraceae (Hodgson et al. 2014), Araliaceae (Soares et al. 2016), Convulvulacea (Cook et al. 2013), Ericaceae (Rayner 1915), Fabaceae (including members of Astragalus, Oxytropis and Swainsona Cook et al. 2009; Cook et al. 2014 Grum et al. 2013), Papaveraceae (Hodgson et al. 2014), and Plantaginaceae (Hodgson et al. 2014). This suggests that facultative vertical-transmission may occur in numerous plant hosts and across many biomes. Cross-biome comparative studies of the seed microbiome could determine if vertical-transmission is more common in certain habitats, as might be predicted if these endophytes interact mutualistically with their hosts to ameliorate the negative affects of particular abiotic conditions (Afkhami et al. 2014; Gundel et al. 2017).

The effects of tissue type on endophyte assemblages

Our vote counting approach suggested that in woody plants stems had higher richness 
than other tissues, for both fungi and bacteria. However, for graminoids, roots were the richest tissue and, for forbs, inter-tissue patterns in richness were less clear (Tables S1 S3). These results suggest that tissues with greater lifetime inocula exposure have the highest richness across plant life histories. Indeed, several studies have demonstrated that older leaves typically harbor richer microbial assemblages than younger leaves, presumably because of greater exposure to inoculum and increased time for microbial growth (Arnold et al. 2003, Ercolani 1991). Stems and bark of woody plants are exposed to inocula in air, water, and dust year round and have long lifespans (indeed much bark is dead and can remain on the trunk for a lengthy period of time), whereas leaves, even for evergreen trees, do not persist for nearly as long. Similarly, roots are the longest-lived tissues of many perennial forbs and graminoids, as above-ground tissues of these hosts often senesce annually. It is true that roots of woody-stemmed plants can be quite long-lived, however roots are primarily encountering inoculum from the surrounding soil matrix, thus it is possible that there is greater variation in the inoculum encountered by stems than by roots over the lives of those tissues. Alternatively, perhaps the resources available to microbes within stems of woody-plants favor higher richness compared to leaves, particularly of latent saprotrophs that catabolize lignin or other structural carbohydrates (Oses et al. 2006; Oses et al. 2008). These hypotheses are not mutually exclusive and await experimental testing.

Our survey comes with several caveats. First, it is possible that the efficacy of surface sterilization may vary with tissue type; thus, for instance, the high fungal richness in bark that we report could be because it was more difficult to surface sterilize than other tissues. Also, while we chose those studies that had the same sample size (in terms of replicates) between each tissue type, it was not always apparent that the same mass was used for each sample. Additionally, both culture and sequence-based surveys suffer from taxonomic biases (Carini 2019; Nilsson et al. 2018) and if those biases coincide with taxonomic variation among tissue types, then richness estimates will be incorrect. Nevertheless, our analysis demonstrates the existence of clear patterns in richness among tissue types and suggests several hypotheses for those patterns that deserve further study.

\section{How can we best share information among studies?}

We report several challenges that impede meta-analysis and synthesis of the endophyte literature (e.g., Meiser et al. 2014). Most importantly, raw and processed sequence data were not always available. Moreover, it was quite rare for sufficient detail to be provided regarding sequence processing - including options and versions for software used and date accessed for taxonomy training databases, which are in constant flux. Given the challenge in reprocessing data and the influence different bioinformatic pipelines can have on results (e.g., Pauvert et al. 2019), we suggest that publication of polished data and scripts should be considered to facilitate information sharing among studies. Those data that would be most amenable to meta-analysis include replicate by taxon tables, sequences of operational taxonomic units (OTUs) or exact sequence variants (ESVs), and the taxonomic hypotheses for those sequences. In many cases, meta-analysis will require substantial reprocessing of the data, so raw data should also be made available.

Additionally, we suggest that authors consider depositing vouchers of host taxa studied, nucleic acids extracted, or cultures obtained, in an herbarium whenever possible (Fig. $2 \mathrm{~d}$ ). This suggestion is motivated, in part, by fascinating new work by Daru et al. (2019) who 
have shown that endophytes within herbarium specimens can be sequenced, and, in some cases, even cultured. Thus, vouchers could act as "time capsules" that preserve endophyte genotypes and could afford insight into endophyte evolution and shifts in host and geographic range over time. To best share information among vouchers, standardized protocols (such as drying time and temperature) could be helpful to adopt, though we acknowledge the challenge of implementing such standards during field collection. Deposited cultures could provide many of the same benefits as host vouchers, but would also allow researchers to grow endophytes of interest to meet various experimental goals (Huang et al. 2018, Suryanarayanan 2019). Finally, the plant taxonomy is ever-changing, thus as future researchers interpret published work, they may wish to examine accessions to determine the most current taxonomic placement of the focal host or endophyte. In sum, we see herbaria as tremendous resources for the study of the plant microbiome, and, consequently, we urge participation in their continued development.

\section{Conclusion}

To understand the evolutionary forces and ecological pressures that shape endophyte assemblages, the delineation of patterns in endophyte biodiversity across spatial scales and the host phylogeny is required. The enthusiasm among microbial ecologists for endophyte biology paired with the tools we now have at our collective disposal, suggests that description of such patterns is within grasp. We hope that our survey inspires others to fill the gaps in knowledge that we report. To that end, we have made the metadata from each study that we consider available (see the Supplemental Material) in hopes that other researchers mine them for additional insights.

\section{Acknowledgments}

Thanks go to Lyra Beltran for assistance extracting data from publications. This review was inspired by conversations with Betsy Arnold, to whom we offer our thanks. We appreciate comments from Leho Tedersoo and two anonymous reviewers that led to a much improved manuscript. JGH was supported by the National Science Foundation EPSCoR grant 1655726. EAG was supported by a Smithsonian Institution Secretary's Distinguished Research Fellowship, as well as a Smithsonian Environmental Research Center Postdoc Research Fellowship, the Maryland Native Plant Society, the Washington Biologists Field Club, and The New Mexico Idea Network of Biomedical Research Excellence (NM-INBRE).

\section{Data availability}

All scripts and processed data are available at:

https://bitbucket.org/harrisonjg/endophytereview/src/master/ 


\section{References}

Afkhami, Michelle E., Patrick J. McIntyre, and Sharon Y. Strauss (2014). "Mutualistmediated effects on species' range limits across large geographic scales". en. In: Ecology Letters 17.10 , pp. 1265-1273.

Allison, Steven D. and Peter M. Vitousek (2004). "Rapid nutrient cycling in leaf litter from invasive plants in Hawai'i". en. In: Oecologia 141.4, pp. 612-619.

Aly, Amal H. et al. (2010). "Fungal endophytes from higher plants: a prolific source of phytochemicals and other bioactive natural products". en. In: Fungal Diversity 41.1, pp. $1-16$.

Andrews, John H. et al. (1987). "Fungi, leaves, and the theory of island biogeography". en. In: Microbial Ecology 14.3, pp. 277-290.

Arnold, A. Elizabeth and Bettina M. J. Engelbrecht (2007). "Fungal endophytes nearly double minimum leaf conductance in seedlings of a neotropical tree species". en. In: Journal of Tropical Ecology 23.3, pp. 369-372.

Arnold, A. Elizabeth and F. Lutzoni (2007). "Diversity and host range of foliar fungal endophytes: are tropical leaves biodiversity hotspots?" en. In: Ecology 88.3, pp. 541-549.

Arnold, A. Elizabeth et al. (2003). "Fungal endophytes limit pathogen damage in a tropical tree". en. In: Proceedings of the National Academy of Sciences 100.26, pp. 15649-15654.

Auret, Theodora B. (1930). "Observations on the reproduction and fungal endophytism of Lunularia cruciata (L.) Dumortier." English. In: Transactions of the British Mycological Society 15.1-2.

Baas Becking, L. G. M. (1934). Geobiologie of inleiding tot de milieukunde. The Hague, the Netherlands: W.P. Van Stockum \& Zoon.

Bary, Anton de (1866). Morphologie und physiologie der Pilze, Flechten und Myxomyceten. de. Leipzig, Germany: W. Engelmann.

Bowman, Elizabeth A. and A. Elizabeth Arnold (2018). "Distributions of ectomycorrhizal and foliar endophytic fungal communities associated with Pinus ponderosa along a spatially constrained elevation gradient". en. In: American Journal of Botany 105.4, pp. 687699.

Brenan, J. P. M. (1978). "Some aspects of the phytogeography of tropical Africa". In: Annals of the Missouri Botanical Garden 65.2, pp. 437-478.

Brooks, Matthew L. et al. (2004). "Effects of invasive alien plants on fire regimes". en. In: BioScience 54.7, pp. 677-688.

Busby, Posy E., Mary Ridout, and George Newcombe (2016). "Fungal endophytes: modifiers of plant disease". en. In: Plant Molecular Biology 90.6, pp. 645-655.

Busby, Posy E. et al. (2017). "Research priorities for harnessing plant microbiomes in sustainable agriculture". en. In: PLOS Biology 15.3, e2001793.

Campbell, Douglas Houghton (1908). "Symbiosis in fern prothalia". In: The American Naturalist 42.495, pp. 154-165.

Carini, Paul (2019). "A "cultural" renaissance: genomics breathes new life into an old craft". en. In: mSystems 4.3, e00092-19.

Carroll, George (1988). "Fungal endophytes in stems and leaves: from latent pathogen to mutualistic symbiont". en. In: Ecology 69.1, pp. 2-9. 
Carroll, George C and Fanny E Carroll (1978). "Studies on the incidence of coniferous needle endophytes in the Pacific Northwest". In: Canadian Journal of Botany 56.24, pp. 30343043.

Chase, Mark W. et al. (2015). "An updated classification of Orchidaceae". en. In: Botanical Journal of the Linnean Society 177.2, pp. 151-174.

Christian, Natalie, Edward Allen Herre, and Keith Clay (2019). "Foliar endophytic fungi alter patterns of nitrogen uptake and distribution in Theobroma cacao". en. In: New Phytologist 222.3, pp. 1573-1583.

Christian, Natalie, Briana K Whitaker, and Keith Clay (2015). "Microbiomes: unifying animal and plant systems through the lens of community ecology theory". In: Frontiers in microbiology 6.

Christian, Natalie et al. (2017). "Exposure to the leaf litter microbiome of healthy adults protects seedlings from pathogen damage". en. In: Proc. R. Soc. B 284.1858, p. 20170641.

Clay, Keith and Jenny Holah (1999). "Fungal endophyte symbiosis and plant diversity in successional fields". en. In: Science 285.5434, pp. 1742-1744.

Clay, Keith and Christopher Schardl (2002). "Evolutionary origins and ecological consequences of endophyte symbiosis with grasses". In: The American Naturalist 160.S4, S99S127.

Coleman-Derr, Devin et al. (2016). "Plant compartment and biogeography affect microbiome composition in cultivated and native Agave species". en. In: New Phytologist 209.2, pp. $798-811$.

Compant, Stéphane, Angela Sessitsch, and Florence Mathieu (2012). "The 125th anniversary of the first postulation of the soil origin of endophytic bacteria - a tribute to M.L.V. Galippe". en. In: Plant and Soil 356.1, pp. 299-301.

Compant, Stéphane et al. (2005). "Use of plant growth-promoting bacteria for biocontrol of plant diseases: principles, mechanisms of action, and future prospects". en. In: Applied and Environmental Microbiology 71.9, pp. 4951-4959.

Cook, Daniel, Dale R. Gardner, and James A. Pfister (2014). "Swainsonine-containing plants and their relationship to endophytic fungi". In: Journal of Agricultural and Food Chemistry 62.30, pp. 7326-7334.

Cook, Daniel et al. (2009). "Swainsoninine concentrations and endophyte amounts of Undifilum oxytropis in different plant parts of Oxytropis sericea". eng. In: Journal of Chemical Ecology 35.10, pp. 1272-1278.

Cook, Daniel et al. (2013). "Production of the alkaloid swainsonine by a fungal endosymbiont of the Ascomycete Order Chaetothyriales in the host Ipomoea carnea". In: Journal of Agricultural and Food Chemistry 61.16, pp. 3797-3803.

Cooper, Harris and Larry V. Hedges (1993). The handbook of research synthesis. en. Russell Sage Foundation.

Crowl, Todd A. et al. (2008). "The spread of invasive species and infectious disease as drivers of ecosystem change". en. In: Frontiers in Ecology and the Environment 6.5, pp. 238-246.

Daru, Barnabas H. et al. (2019). "A novel proof of concept for capturing the diversity of endophytic fungi preserved in herbarium specimens". In: Philosophical Transactions of the Royal Society B: Biological Sciences 374.1763, p. 20170395. 
Davis, E. Christine and A. Jonathan Shaw (2008). "Biogeographic and phylogenetic patterns in diversity of liverwort-associated endophytes". en. In: American Journal of Botany 95.8, pp. 914-924.

Desirò Alessandro et al. (2013). "Fungal symbioses in hornworts: a chequered history". In: Proceedings of the Royal Society B: Biological Sciences 280.1759, p. 20130207.

Dickie, Ian A. et al. (2017). "The emerging science of linked plant-fungal invasions". en. In: New Phytologist 215.4, pp. 1314-1332.

Dietz, Thomas, Eugene A. Rosa, and Richard York (2007). "Driving the human ecological footprint". en. In: Frontiers in Ecology and the Environment 5.1, pp. 13-18.

Doty, Sharon Lafferty (2011). "Growth-promoting endophytic fungi of forest trees". en. In: Endophytes of Forest Trees: Biology and Applications. Ed. by Anna Maria Pirttilä and A. Carolin Frank. Forestry Sciences. Dordrecht: Springer Netherlands, pp. 151-156.

Ercolani, G. L. (1991). "Distribution of epiphytic bacteria on olive leaves and the influence of leaf age and sampling time". en. In: Microbial Ecology 21.1, pp. 35-48.

Federhen, Scott (2012). "The NCBI Taxonomy database". In: Nucleic Acids Research 40.Database issue, pp. D136-D143.

Forister, Matthew L. (2009). "Anthropogenic islands in the arid West: comparing the richness and diversity of insect communities in cultivated fields and neighboring wildlands". In: Environmental Entomology 38.4, pp. 1028-1037.

Frank, B. (1885). "Ueber die auf Wurzelsymbiose beruhende Ernährung gewisser Bäume durch unterirdische Pilze". en. In: Berichte der Deutschen Botanischen Gesellschaft 3.4, pp. $128-145$.

- (2005). "On the nutritional dependence of certain trees on root symbiosis with belowground fungi (an English translation of A.B. Frank's classic paper of 1885)". en. In: Mycorrhiza 15.4, pp. 267-275.

Friesen, Maren L. et al. (2011). "Microbially mediated plant functional traits". In: Annual Review of Ecology, Evolution, and Systematics 42.1, pp. 23-46.

Galippe, V (1887). "Note sur la présence de micro-organismes dans les tissus végétaux." In: Comptes Rendus des Seances de la Societe de Biologie et de ses Filiales 39, pp. 410-416.

Gazis, Romina and Priscila Chaverri (2015). "Wild trees in the Amazon basin harbor a great diversity of beneficial endosymbiotic fungi: is this evidence of protective mutualism?" In: Fungal Ecology 17, pp. 18-29.

Giauque, Hannah and Christine V Hawkes (2013). "Climate affects symbiotic fungal endophyte diversity and performance". In: American journal of botany 100.7, pp. 1435-1444.

Glynou, Kyriaki et al. (2016). "The local environment determines the assembly of root endophytic fungi at a continental scale". en. In: Environmental Microbiology 18.8, pp. 24182434.

Golan, Jacob J. and Anne Pringle (2017). "Long-distance dispersal of fungi". eng. In: $M i$ crobiology Spectrum 5.4.

Granzow, Sandra et al. (2017). "The effects of cropping regimes on fungal and bacterial communities of wheat and faba bean in a greenhouse pot experiment differ between plant species and compartment". English. In: Frontiers in Microbiology 8.

Griffin, Eric A. and Walter P. Carson (2015). "The ecology and natural history of foliar bacteria with a focus on tropical forests and agroecosystems". en. In: The Botanical Review 81.2, pp. 105-149. 
Griffin, Eric A. et al. (2016). "Foliar bacteria and soil fertility mediate seedling performance: a new and cryptic dimension of niche differentiation". en. In: Ecology 97.11, pp. 29983008.

Griffin, Eric A. et al. (2017). "Pervasive interactions between foliar microbes and soil nutrients mediate leaf production and herbivore damage in a tropical forest". en. In: New Phytologist 216.1, pp. 99-112.

Griffin, Eric A. et al. (2019). "Plant host identity and soil macronutrients explain little variation in sapling endophyte community composition: is disturbance an alternative explanation?" In: Journal of Ecology 107.4, pp. 1876-1889.

Grum, Daniel S. et al. (2013). "Production of the alkaloid swainsonine by a fungal endophyte in the host Swainsona canescens". eng. In: Journal of Natural Products 76.10, pp. 19841988.

Gundale, Michael J. et al. (2016). "Differences in endophyte communities of introduced trees depend on the phylogenetic relatedness of the receiving forest". en. In: Journal of Ecology 104.5, pp. 1219-1232.

Gundel, Pedro E., Jennifer A. Rudgers, and Kenneth D. Whitney (2017). "Vertically transmitted symbionts as mechanisms of transgenerational effects". en. In: American Journal of Botany 104.5, pp. 787-792.

Hanson, China A. et al. (2012). "Beyond biogeographic patterns: processes shaping the microbial landscape". en. In: Nature Reviews Microbiology 10.7, pp. 497-506.

Hardoim, Pablo R., Leo S. van Overbeek, and Jan Dirk van Elsas (2008). "Properties of bacterial endophytes and their proposed role in plant growth". In: Trends in Microbiology 16.10, pp. 463-471.

Hardoim, Pablo R. et al. (2015). "The hidden world within plants: ecological and evolutionary considerations for defining functioning of microbial endophytes". en. In: Microbiology and Molecular Biology Reviews 79.3, pp. 293-320.

Haruna, Emmanuel et al. (2018). "Extensive overlap of tropical rainforest bacterial endophytes between soil, plant parts, and plant species". en. In: Microbial Ecology 75.1, pp. 88103.

Hassani, M. Amine et al. (2019). "Interactions and coadaptation in plant metaorganisms". In: Annual Review of Phytopathology 57.1, null.

Helander, M. L. et al. (1994). "Endophytic fungi in Scots pine needles: spatial variation and consequences of simulated acid rain". In: Canadian Journal of Botany 72.8, pp. 11081113.

Helander, M. et al. (2007). "Fragmented environment affects birch leaf endophytes". en. In: New Phytologist 175.3, pp. 547-553.

Herre, Edward Allen et al. (2007). "Ecological implications of anti-pathogen effects of tropical fungal endophytes and mycorrhizae". en. In: Ecology 88.3, pp. 550-558.

Higginbotham, Sarah J. et al. (2013). "Bioactivity of fungal endophytes as a function of endophyte taxonomy and the taxonomy and distribution of their host plants". en. In: PLOS ONE 8.9, e73192.

Higgins, K Lindsay et al. (2014). "Communities of fungal endophytes in tropical forest grasses: highly diverse host-and habitat generalists characterized by strong spatial structure". In: Fungal Ecology 8, pp. 1-11. 
Hodgson, Susan et al. (2014). "Vertical transmission of fungal endophytes is widespread in forbs". en. In: Ecology and Evolution 4.8, pp. 1199-1208.

Huang, Yu-Ling et al. (2018). "Using collections data to infer biogeographic, environmental, and host structure in communities of endophytic fungi". In: Mycologia 110.1, pp. 47-62.

Hubbell, Stephen (2001). The unified neutral theory of biodiversity and biogeography. Princeton, New Jersey: Princeton University Press.

Hyde, K. D. and K Soytong (2008). "The fungal endophyte dilemma". In: Fungal Diversity 33.163, e173.

Lu-Irving, Patricia et al. (2019). "Native and invading yellow starthistle (Centaurea solstitialis) microbiomes differ in composition and diversity of bacteria". en. In: mSphere 4.2 .

Janse, J. M. (1897). "Les endophytes radicaux de quelques plantes javanaises." In: Ann Jardin Bot Buitenzorg 14, pp. 53-201.

Jumpponen, Ari (2001). "Dark septate endophytes - are they mycorrhizal?" en. In: Mycorrhiza 11.4, pp. 207-211.

Jumpponen, Ari et al. (2017). "Biogeography of root-associated fungal endophytes". en. In: Biogeography of Mycorrhizal Symbiosis. Ed. by Leho Tedersoo. Ecological Studies. Cham: Springer International Publishing, pp. 195-222.

Jurc, Maja et al. (1996). "Air pollution and fungal endophytes in needles of Austrian pine". In: Phyton 36, pp. 111-114.

Kew and Missouri Botanical Gardens (2019). The Plant List, http://www.theplantlist.org/.

Kharwar, R. N. et al. (2011). "Anticancer compounds derived from fungal endophytes: their importance and future challenges". en. In: Natural Product Reports 28.7, pp. 1208-1228.

Kivlin, Stephanie N., Sarah M. Emery, and Jennifer A. Rudgers (2013). "Fungal symbionts alter plant responses to global change". en. In: American Journal of Botany 100.7, pp. 14451457.

Kivlin, Stephanie N. et al. (2019). "Plant identity influences foliar fungal symbionts more than elevation in the Colorado Rocky Mountains". en. In: Microbial Ecology, pp. 1-11.

Koenig, Robert (2008). "Critical time for African rainforests". en. In: Science 320.5882, pp. 1439-1441.

Kusari, Souvik, Christian Hertweck, and Michael Spiteller (2012). "Chemical ecology of endophytic fungi: origins of secondary metabolites". In: Chemistry \& Biology 19.7, pp. 792798.

Laforest-Lapointe, Isabelle, Christian Messier, and Steven W. Kembel (2017a). "Tree leaf bacterial community structure and diversity differ along a gradient of urban intensity". en. In: mSystems 2.6, e00087-17.

Laforest-Lapointe, Isabelle et al. (2017b). "Leaf bacterial diversity mediates plant diversity and ecosystem function relationships". en. In: Nature 546.7656, pp. 145-147.

Lappalainen, J. H et al. (1999). "Densities of endophytic fungi and performance of leafminers (Lepidoptera: Eriocraniidae) on birch along a pollution gradient". In: Environmental Pollution 104.1, pp. 99-105.

Lau, Matthew K., A. Elizabeth Arnold, and Nancy Collins Johnson (2013). "Factors influencing communities of foliar fungal endophytes in riparian woody plants". en. In: Fungal Ecology 6.5, pp. 365-378. 
Laurent, Émile (1889). "Sur l'existence de microbes dans les tissus des plantes supérieures". In: Bulletin de la Société Royale de Botanique de Belgique Bulletin van de Koninklijke Belgische Botanische Vereniging 28, pp. 233-244.

Letunic, Ivica and Peer Bork (2016). "Interactive tree of life (iTOL) v3: an online tool for the display and annotation of phylogenetic and other trees". en. In: Nucleic Acids Research 44.W1, W242-W245.

Lindblom, Stormy Dawn et al. (2013). "Influence of microbial associations on selenium localization and speciation in roots of Astragalus and Stanleya hyperaccumulators". In: Environmental and Experimental Botany. Plant Functioning in a Changing Global and Polluted Environment 88, pp. 33-42.

Lindblom, Stormy Dawn et al. (2018). "Fungal endophyte Alternaria tenuissima can affect growth and selenium accumulation in its hyperaccumulator host Astragalus bisulcatus". English. In: Frontiers in Plant Science 9.

Linder, H. P. (2001). "Plant diversity and endemism in sub-Saharan tropical Africa". en. In: Journal of Biogeography 28.2, pp. 169-182.

Link, H. F. (1809). "Observationes in ordines plantarum naturales, dissertatio prima, complectens anandrarum ordines Epiphytas, Mucedines, Gastromycos et Fungos." In: Der Gesellschaft Naturforschender Freunde zu Berlin 3, pp. 3-42.

Lodge, D Jean, PJ Fisher, and BC Sutton (1996). "Endophytic fungi of Manilkara bidentata leaves in Puerto Rico". In: Mycologia, pp. 733-738.

Lopez, Blanca R., Yoav Bashan, and Macario Bacilio (2011). "Endophytic bacteria of Mammillaria fraileana, an endemic rock-colonizing cactus of the southern Sonoran Desert". en. In: Archives of Microbiology 193.7, pp. 527-541.

Lynch, Michael D. J. and Josh D. Neufeld (2015). "Ecology and exploration of the rare biosphere". en. In: Nature Reviews Microbiology 13.4, pp. 217-229.

MacArthur, Robert H. and Edward O. Wilson (2001). The Theory of Island Biogeography. en. Google-Books-ID: a10cdkywhVgC. Princeton University Press.

Malloch, David and Meredith Blackwell (1992). "Dispersal of fungal diaspores". In: The fungal community: its organization and role in the ecosystem. Second Edition. New York, NY: Marcel Dekker, Inc, pp. 147-171.

Márquez, Luis M. et al. (2007). "A virus in a fungus in a plant: three-way symbiosis required for thermal tolerance". en. In: Science 315.5811, pp. 513-515.

Martiny, Jennifer B. Hughes et al. (2006). "Microbial biogeography: putting microorganisms on the map". en. In: Nature Reviews Microbiology 4.2, pp. 102-112.

Massimo, Nicholas C. et al. (2015). "Fungal endophytes in aboveground tissues of desert plants: infrequent in culture, but highly diverse and distinctive symbionts". en. In: $M i$ crobial Ecology 70.1, pp. 61-76.

Massoni, Julien et al. (2019). "Consistent host and organ occupancy of phyllosphere bacteria in a community of wild herbaceous plant species". en. In: The ISME Journal, pp. 1-14.

Meiser, Anjuli, Miklós Bálint, and Imke Schmitt (2014). "Meta-analysis of deep-sequenced fungal communities indicates limited taxon sharing between studies and the presence of biogeographic patterns". In: New Phytologist 201.2, pp. 623-635.

Mittelbach, Gary G. et al. (2007). "Evolution and the latitudinal diversity gradient: speciation, extinction and biogeography". en. In: Ecology Letters 10.4, pp. 315-331. 
Moeller, Holly V. et al. (2015). "Mycorrhizal co-invasion and novel interactions depend on neighborhood context". en. In: Ecology 96.9, pp. 2336-2347.

Moissl-Eichinger, Christine et al. (2018). "Archaea are interactive components of complex microbiomes". In: Trends in Microbiology 26.1, pp. 70-85.

Müller, Henry et al. (2015). "Plant genotype-specific archaeal and bacterial endophytes but similar Bacillus antagonists colonize Mediterranean olive trees". English. In: Frontiers in Microbiology 6.

Neill, J. C. (1940). "The endophyte of rye-grass (Lolium perenne)." English. In: New Zealand Journal of Science and Technology, Section A 21.5.

Nemergut, Diana R. et al. (2013). "Patterns and processes of microbial community assembly". en. In: Microbiology and Molecular Biology Reviews 77.3, pp. 342-356.

Newcombe, George et al. (2018). "A hypothetical bottleneck in the plant microbiome". English. In: Frontiers in Microbiology 9.

Newman, David J., Gordon M. Cragg, and Kenneth M. Snader (2003). "Natural products as sources of new drugs over the period 1981-2002". In: Journal of Natural Products 66.7, pp. 1022-1037.

Nilsson, R. Henrik et al. (2018). "Mycobiome diversity: high-throughput sequencing and identification of fungi". En. In: Nature Reviews Microbiology, p. 1.

Oksanen, Jari et al. (2016). "vegan: community ecology package". In: CRAN.

Olson, David M. et al. (2001). "Terrestrial ecoregions of the world: a new map of life on earth". en. In: BioScience 51.11, pp. 933-938.

Oono, Ryoko, Anna Rasmussen, and Emilie Lefèvre (2017). "Distance decay relationships in foliar fungal endophytes are driven by rare taxa". en. In: Environmental Microbiology 19.7, pp. 2794-2805.

Oses, Rómulo et al. (2006). "Evaluation of fungal endophytes for lignocellulolytic enzyme production and wood biodegradation". In: International Biodeterioration $\&$ Biodegradation 57.2, pp. 129-135.

Oses, Rómulo et al. (2008). "Fungal endophytes in xylem of healthy Chilean trees and their possible role in early wood decay". In: Fungal Diversity 33.7, pp. 77-86.

Panaccione, Daniel G., Wesley T. Beaulieu, and Daniel Cook (2014). "Bioactive alkaloids in vertically transmitted fungal endophytes". en. In: Functional Ecology 28.2, pp. 299-314.

Pauvert, Charlie et al. (2019). "Bioinformatics matters: The accuracy of plant and soil fungal community data is highly dependent on the metabarcoding pipeline". In: Fungal Ecology 41, pp. 23-33.

Peay, Kabir G., Martin I. Bidartondo, and A. Elizabeth Arnold (2010). "Not every fungus is everywhere: scaling to the biogeography of fungal-plant interactions across roots, shoots and ecosystems". en. In: New Phytologist 185.4, pp. 878-882.

Peay, Kabir G. et al. (2007). "A strong species-area relationship for eukaryotic soil microbes: island size matters for ectomycorrhizal fungi". en. In: Ecology Letters 10.6. Citation Key Alias: peay_strong_2007-1, pp. 470-480.

Peter, J., W. Young, and Kaisa E. Haukka (1996). "Diversity and phylogeny of rhizobia". en. In: New Phytologist 133.1, pp. 87-94.

Petrini, Orlando (1991). "Fungal endophytes of tree leaves". en. In: Microbial Ecology of Leaves. Ed. by John H. Andrews and Susan S. Hirano. Brock/Springer Series in Contemporary Bioscience. Springer New York, pp. 179-197. 
Pianka, Eric R. (1966). "Latitudinal gradients in species diversity: a review of concepts". In: The American Naturalist 100.910, pp. 33-46.

R Core Team (2019). R: A language and environment for statistical computing. tex.organization: R Foundation for Statistical Computing. Vienna, Austria.

Rayner, M. Cheveley (1915). "Obligate symbiosis in Calluna vulgaris". In: Annals of Botany 29.113, pp. 97-133.

Redford, Amanda J. et al. (2010). "The ecology of the phyllosphere: geographic and phylogenetic variability in the distribution of bacteria on tree leaves". en. In: Environmental Microbiology 12.11. Citation Key Alias: redford_ecology_2010-1, pp. 2885-2893.

Redman, Regina S. et al. (2002). "Thermotolerance generated by plant/fungal symbiosis". en. In: Science 298.5598, pp. 1581-1581.

Remus-Emsermann, Mitja N. P. and Rudolf O. Schlechter (2018). "Phyllosphere microbiology: at the interface between microbial individuals and the plant host". In: New Phytologist 0.0 .

Rodriguez, RJ et al. (2009). "Fungal endophytes: diversity and functional roles". In: New Phytologist 182.2, pp. 314-330.

Rodriguez, Rusty J. et al. (2008). "Stress tolerance in plants via habitat-adapted symbiosis". en. In: The ISME Journal 2.4, pp. 404-416.

Rojas-Jimenez, Keilor et al. (2016). "Richness of cultivable endophytic fungi along an altitudinal gradient in wet forests of Costa Rica". In: Fungal Ecology 20, pp. 124-131.

Rosa, Luiz H. et al. (2009). "Endophytic fungi associated with the Antarctic grass Deschampsia antarctica Desv. (Poaceae)". en. In: Polar Biology 32.2, pp. 161-167.

Rudgers, Jennifer A. et al. (2009). "A fungus among us: broad patterns of endophyte distribution in the grasses". en. In: Ecology 90.6, pp. 1531-1539.

Ryan, Robert P. et al. (2008). "Bacterial endophytes: recent developments and applications". en. In: FEMS Microbiology Letters 278.1, pp. 1-9.

Saikkonen, K. et al. (1998). "Fungal endophytes: a continuum of interactions with host plants". In: Annual Review of Ecology and Systematics 29, pp. 319-343.

Sampson, Kathleen (1937). "Further observations on the systemic infection of Lolium". In: Transactions of the British Mycological Society 21.1, 84-IN9.

Sangamesh, M. B. et al. (2017). "Thermotolerance of fungal endophytes isolated from plants adapted to the Thar Desert, India". en. In: Symbiosis, pp. 1-13.

Schulz, Barbara and Christine Boyle (2005). "The endophytic continuum". In: Mycological Research 109.6, pp. 661-686.

- (2006). "What are endophytes?" en. In: Microbial Root Endophytes. Ed. by Barbara J. E. Schulz, Christine J. C. Boyle, and Thomas N. Sieber. Soil Biology. Berlin, Heidelberg: Springer Berlin Heidelberg, pp. 1-13.

Schulz, Barbara et al. (2002). "Endophytic fungi: a source of novel biologically active secondary metabolites**Paper presented at the British Mycological Society symposium on Fungal Bioactive Compounds, held at the University of Wales Swansea on 22-27 April 2001." In: Mycological Research 106.9, pp. 996-1004.

Shaffer, Justin P. et al. (2016). "Diversity, specificity, and phylogenetic relationships of endohyphal bacteria in fungi that Inhabit tropical seeds and leaves". English. In: Frontiers in Ecology and Evolution 4. 
Shipunov, Alexey et al. (2008). "Hidden diversity of endophytic fungi in an invasive plant". en. In: American Journal of Botany 95.9, pp. 1096-1108.

Sikes, Benjamin A., Christine V. Hawkes, and Tadashi Fukami (2016). "Plant and root endophyte assembly history: interactive effects on native and exotic plants". en. In: Ecology 97.2, pp. 484-493.

Soares, Marcos Antônio et al. (2016). "Functional role of an endophytic Bacillus amyloliquefaciens in enhancing growth and disease protection of invasive English ivy (Hedera helix L.)" en. In: Plant and Soil 405.1, pp. 107-123.

Stone, Jeffrey K, Charles W Bacon, and JF White (2000). "An overview of endophytic microbes: endophytism defined". In: Microbial endophytes 3, pp. 29-33.

Strobel, Gary and Bryn Daisy (2003). "Bioprospecting for microbial endophytes and their natural products". en. In: Microbiology and Molecular Biology Reviews 67.4, pp. 491-502.

Strobel, Gary et al. (2004). "Natural products from endophytic microorganisms". In: Journal of Natural Products 67.2, pp. 257-268.

Strobel, GA et al. (1996). "Taxol from fungal endophytes and the issue of biodiversity". en. In: Journal of Industrial Microbiology 17.5, pp. 417-423.

Sura-de Jong, Martina et al. (2015). "Selenium hyperaccumulators harbor a diverse endophytic bacterial community characterized by high selenium resistance and plant growth promoting properties". English. In: Frontiers in Plant Science 6.

Suryanarayanan, T S (2019). "Repository of fungal endophytes at VINSTROM, Chennai: waiting to be harnessed". en. In: Current Science 117.9, p. 6.

Suryanarayanan, T S, T S Murali, and G Venkatesan (2002). "Occurrence and distribution of fungal endophytes in tropical forests across a rainfall gradient". In: Canadian Journal of Botany 80.8, pp. 818-826.

Suryanarayanan, T. S. et al. (2011). "Endophytic fungal communities in woody perennials of three tropical forest types of the Western Ghats, southern India". en. In: Biodiversity and Conservation 20.5, pp. 913-928.

Suryanarayanan, Trichur S. (2018). "The host range of multi-host endophytic fungi". In: Current Science.

Taylor, J. E., K. D. Hyde, and E. B. G. Jones (1999). "Endophytic fungi associated with the temperate palm, Trachycarpus fortunei, within and outside its natural geographic range". en. In: The New Phytologist 142.2, pp. 335-346.

Tedersoo, Leho et al. (2014). "Global diversity and geography of soil fungi". en. In: Science 346.6213, p. 1256688.

Tóth, Márta Dobroné, Judit L. Halász, and Sándor Balázsy (2009). "Phyllospheric microbial populations of ragweed (Ambrosia elatior L.) plant grown in toxic metal-contaminated areas". In: Archives of Agronomy and Soil Science 55.2, pp. 217-231.

Trappe, James M. (2005). "A.B. Frank and mycorrhizae: the challenge to evolutionary and ecologic theory". en. In: Mycorrhiza 15.4, pp. 277-281.

Truyens, Sascha et al. (2015). "Bacterial seed endophytes: genera, vertical transmission and interaction with plants". en. In: Environmental Microbiology Reports 7.1, pp. 40-50.

Unterseher, Martin et al. (2018). "Mycobiomes of sympatric Amorphophallus albispathus (Araceae) and Camellia sinensis (Theaceae) - a case study reveals clear tissue preferences and differences in diversity and composition". en. In: Mycological Progress 17.4, pp. 489500 . 
Vacher, Corinne, Tristan Cordier, and Jessica Vallance (2016). "Phyllosphere fungal communities differentiate more thoroughly than bacterial communities along an elevation gradient". en. In: Microbial Ecology 72.1, pp. 1-3.

Vellend, M (2010). "Conceptual synthesis in community ecology." eng. In: The Quarterly review of biology 85.2, pp. 183-206.

Verma, Vijay C., Ravindra N. Kharwar, and Gary A. Strobel (2009). "Chemical and functional diversity of natural products from plant associated endophytic fungi". en. In: Natural Product Communications 4.11, p. 1934578X0900401114.

Viechtbauer, Wolfgang (2010). "Conducting meta-analyses in R with the metafor package". en. In: Journal of Statistical Software 36.1, pp. 1-48.

Vincent, JB, GD Weiblen, and G May (2015). "Host associations and beta diversity of fungal endophyte communities in New Guinea rainforest trees". In: Molecular ecology.

Wiens, John J. and Michael J. Donoghue (2004). "Historical biogeography, ecology and species richness". In: Trends in Ecology \& Evolution 19.12, pp. 639-644.

Willems, Anne (2006). "The taxonomy of rhizobia: an overview". en. In: Plant and Soil 287.1, pp. $3-14$.

Wilson, Dennis (1995). "Endophyte: the evolution of a term, and clarification of its use and definition". In: Oikos, pp. 274-276.

Wolfe, Emily R. et al. (2018). "Differences in foliar endophyte communities of red alder (Alnus rubra) exposed to varying air pollutant levels". In: Botany 96.12, pp. 825-835.

Zimmerman, Naupaka B and Peter M Vitousek (2012). "Fungal endophyte communities reflect environmental structuring across a Hawaiian landscape". In: Proceedings of the National Academy of Sciences 109.32, pp. 13022-13027. 


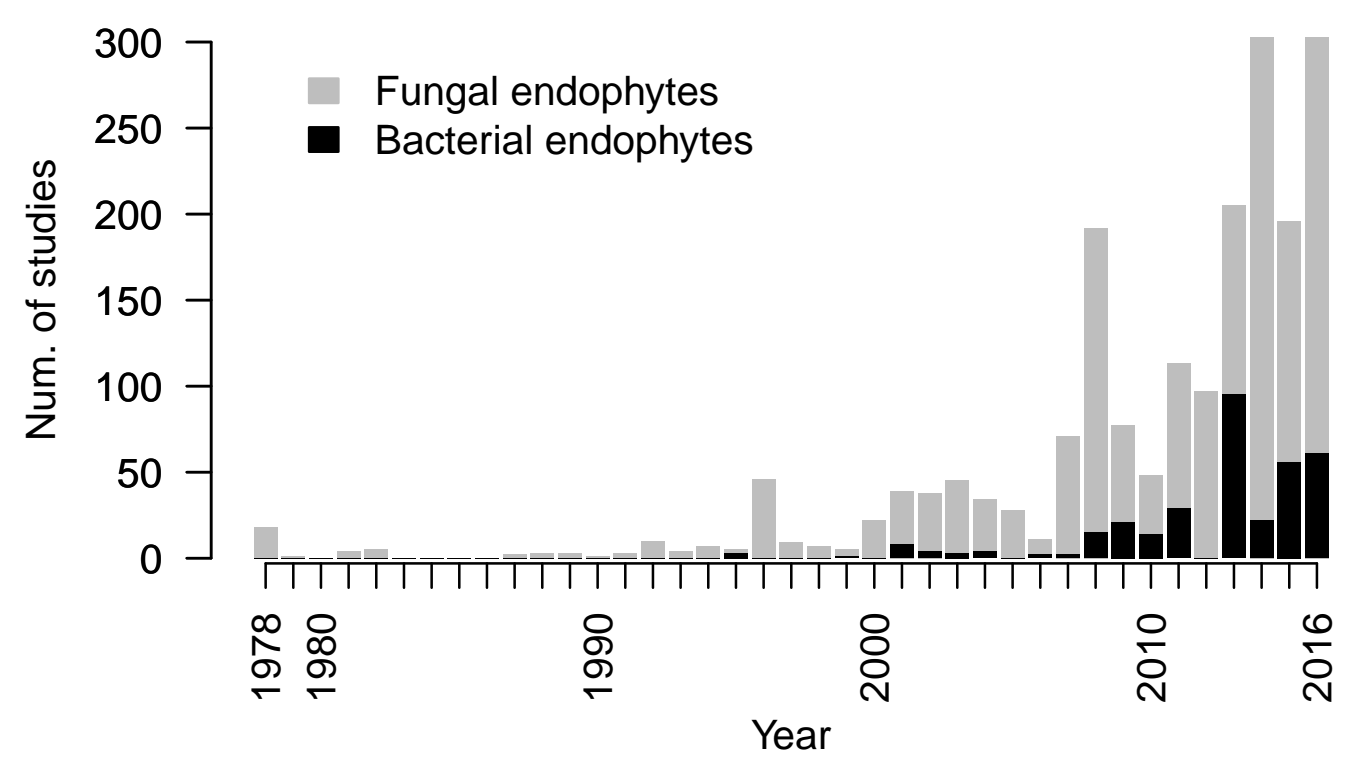

Figure 1: The number of studies characterizing endophyte biodiversity published each year since the late 1970s. Studies are parsed by taxonomy with fungal studies in gray and bacterial studies in black. 
(a)

(b)

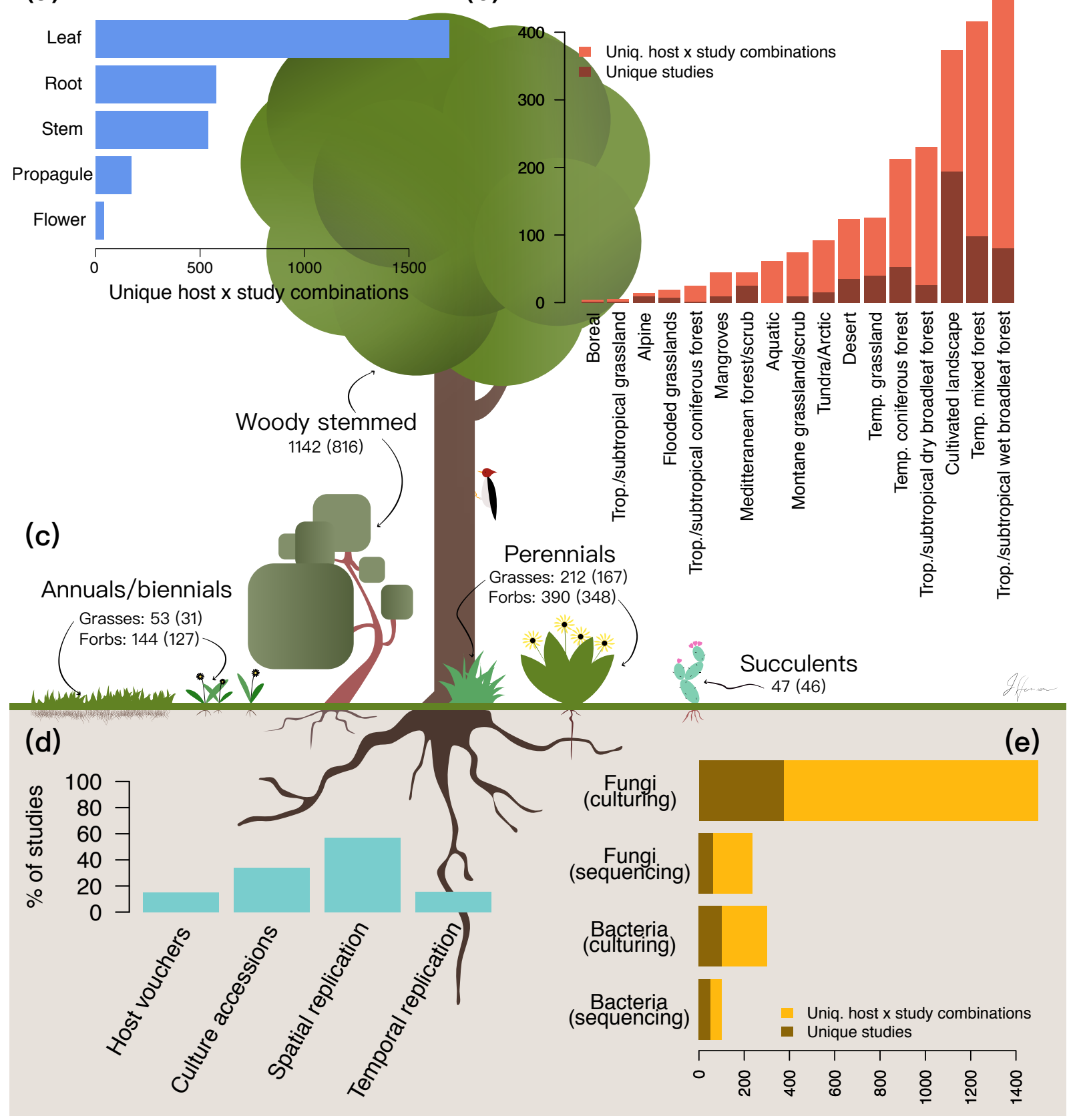

Figure 2: Summary of 596 publications characterizing endophyte biodiversity. Because many studies surveyed multiple hosts, we report both number of studies and number of unique host by study combinations. We counted the number of studies surveying each plant compartment (a), biome (b), and host life history category (c; values in parentheses are unique hosts). We also extracted information pertaining to study design and reproducibility (d). Finally, we determined the endophytic taxon characterized and the methodology employed (e). 


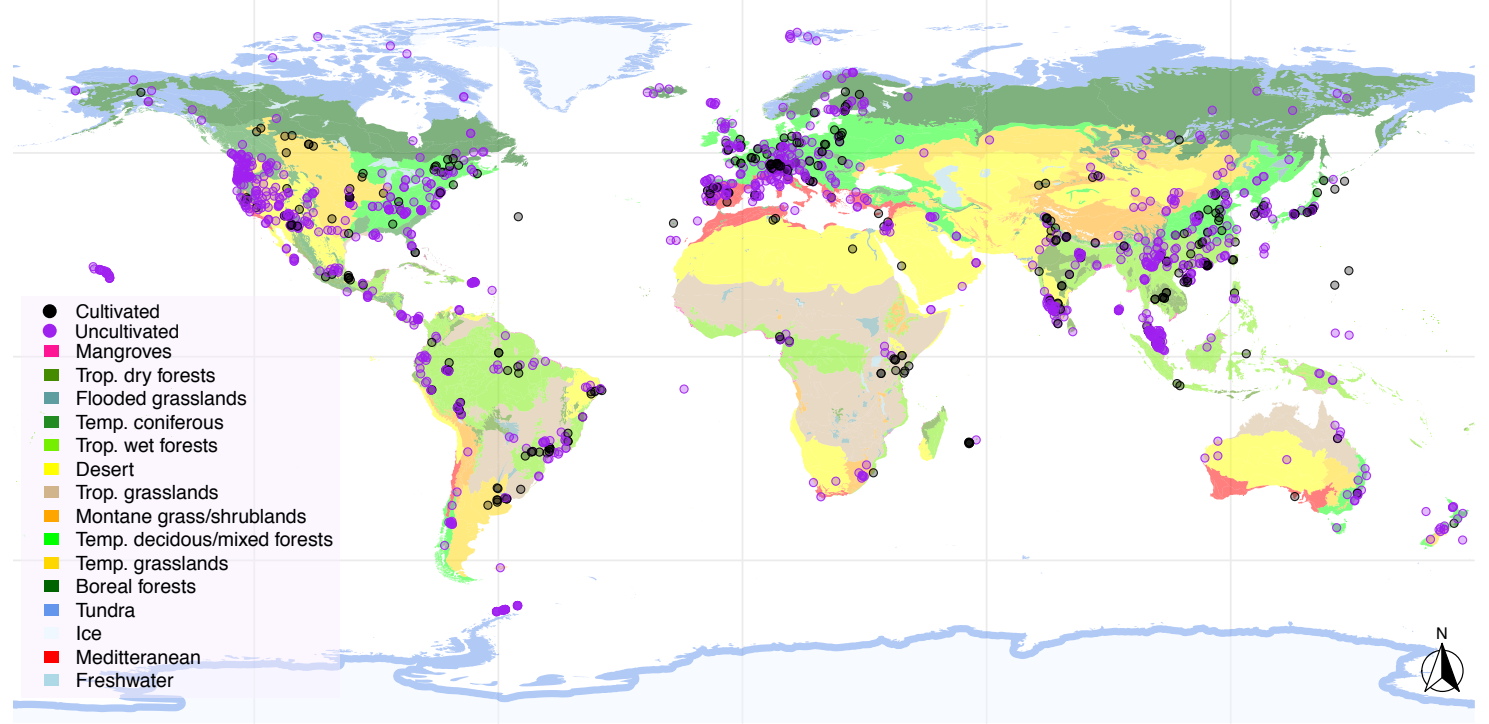

Figure 3: Locations of studies considered. An interactive, zoomable version of this map can be found at: https://jharrisonecoevo.github.io/EndophyteMap/. Black points represent studies of cultivated crops and managed landscapes, purple points represent studies of uncultivated plants in unmanaged settings. Biomes are color coded and delineated in accordance with Olson et al. (2001). In some cases, multiple, proximal locations were surveyed and a single point was used to graphically represent these locations. If a study did not provide exact location information then study location was approximated. 


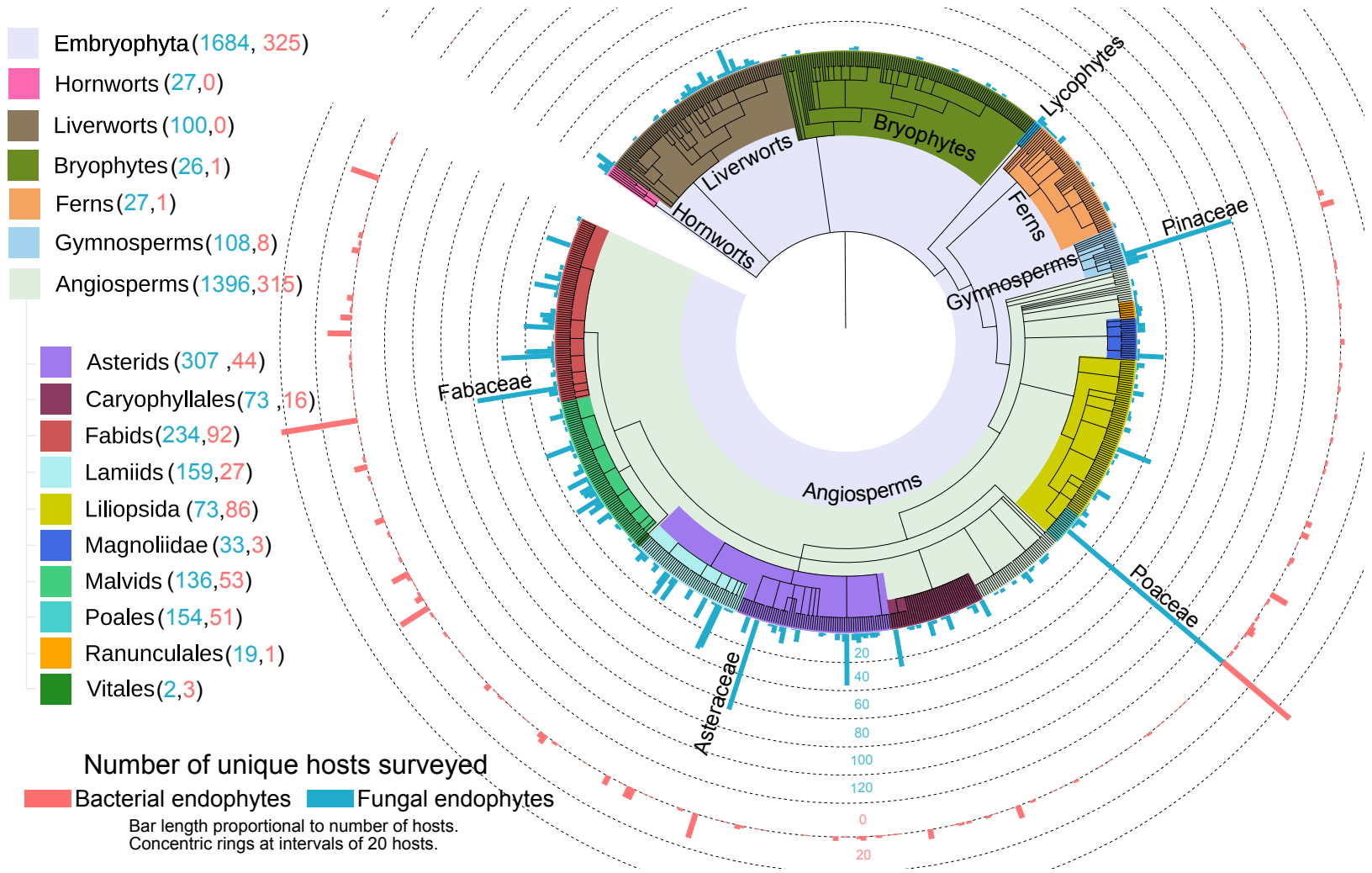

Figure 4: Survey effort across Embryophyta. Number of studies surveying fungal (blue) and bacterial (red) endophytes are shown extending outwards from the tips of the phylogeny. Tips are families. Notable taxa within Embryophyta are labeled and color-coded. Numbers in parentheses denote unique hosts surveyed. Very few surveys of bacterial endophytes have been conducted in bryophyte hosts, therefore this portion of the figure has been abbreviated to aid visualization. An interactive, zoomable version of this phylogeny can be found at: https://itol.embl.de/shared/harrisonjg. 


\section{Supplementary Material}

\section{Meta-analysis methods and results}

We attempted to perform a meta-analysis to examine relative richness of endophytes among plant tissue types. For this analysis, we omitted those studies that did not standardize observational effort among tissues by either mass or sample count (i.e., the number of samples from each tissue type). We also only considered studies that provided a table describing the counts of each microbial taxon observed within each sample (e.g., an operational taxonomic unit [OTU] table), because these data were required to calculate diversity and richness indices. Out of the 558 studies that examined multiple tissues, nine met these criteria for fungi. For bacteria, only a single study met these criteria, precluding a formal meta-analysis, thus for this taxon we only performed vote counting. We rarefied each OTU table by the minimum number of observations for a sample within that study and calculated richness and exponentiated Shannon's diversity for each sample. Calculations were performed using the vegan $R$ package v2.5-5(Oksanen et al. 2016). A random effects model was used to estimate differences in richness and diversity between tissue types while accounting for among-study variation. Models were implemented using the metafor v2.1-0 (Viechtbauer 2010) R package using a restricted maximum likelihood estimation approach.

Across all hosts considered via meta-analysis, we found no significantly supported differences among tissue types in richness or Shannon's diversity (Figs. S1 \& S2). 
Table S1: Differences among host tissues in fungal (top panel) and bacterial (bottom panel) endophyte richness in woody plants. Each cell in the table provides the number of times the tissue type on that row (the focal tissue) had higher richness than the tissue type in that column (the comparison tissue) followed by the number of studies reviewed for each comparison in parentheses. Significance was determined using a binomial sign test. For results from herbaceous plants see Table S2, for results from graminoids see Table $\mathrm{S} 3$

\begin{tabular}{|c|c|c|c|c|c|c|c|}
\hline \multicolumn{8}{|c|}{ Comparison tissue (Fungi) } \\
\hline & & Leaf & Root & Stem & Propagule & Flower & Bark \\
\hline \multirow{6}{*}{ 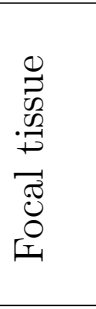 } & Leaf $>$ & - & $4(7)$ & $10(43)^{* * *}$ & $3(4)$ & $2(3)$ & $0(4)$ \\
\hline & Root $>$ & $3(7)$ & - & $1(7)$ & $0(2)$ & $1(2)$ & $0(1)$ \\
\hline & Stem $>$ & $33(43)^{* * *}$ & $6(7)$ & - & $3(3)$ & $2(3)$ & $1(2)$ \\
\hline & Propagule $>$ & $1(4)$ & $2(2)$ & $0(3)$ & - & $0(1)$ & $0(0)$ \\
\hline & Flower $>$ & $1(3)$ & $1(2)$ & $1(3)$ & $1(1)$ & - & $0(0)$ \\
\hline & Bark > & $4(4)$ & $1(1)$ & $1(2)$ & $0(0)$ & $0(0)$ & - \\
\hline \multicolumn{8}{|c|}{ Comparison tissue (Bacteria) } \\
\hline & & & Leaf & Root & Stem & & \\
\hline \multirow{3}{*}{\multicolumn{2}{|c|}{ 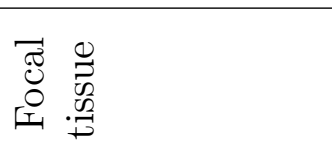 }} & Leaf $>$ & - & $2(7)$ & $3(8)$ & & \\
\hline & & Root $>$ & $5(7)$ & - & $4(6)$ & & \\
\hline & & Stem $>$ & $5(8)$ & $1(6)$ & - & & \\
\hline
\end{tabular}


Table S2: Differences among host tissues in fungal (top panel) and bacterial (bottom panel) endophyte richness in herbaceous plants. Each cell in the table provides the number of times the tissue type on that row (the focal tissue) had higher richness than the tissue type in that column (the comparison tissue) followed by the number of studies reviewed for each comparison in parentheses. Significance was determined using a binomial sign test. For results from woody plants see Table S1, for results from graminoids see Table S3

\begin{tabular}{|c|c|c|c|c|c|}
\hline \multicolumn{6}{|c|}{ Comparison tissue (Fungi) } \\
\hline & & Leaf & Root & Stem & Propagule \\
\hline \multirow{4}{*}{ 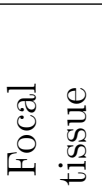 } & Leaf $>$ & - & $9(22)$ & $11(21)$ & $4(5)$ \\
\hline & Root $>$ & $9(21)$ & - & $10(18)$ & $4(5)$ \\
\hline & Stem $>$ & $8(21)$ & $6(18)$ & - & $3(4)$ \\
\hline & Propagule $>$ & $1(5)$ & $1(5)$ & $1(4)$ & - \\
\hline
\end{tabular}

Comparison tissue (Bacteria)

\begin{tabular}{|c|c|c|c|c|}
\hline & & Leaf & Root & Stem \\
\hline \multirow{3}{*}{ 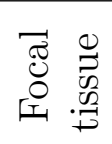 } & Leaf > & - & $1(6)$ & $1(5)$ \\
\hline & Root $>$ & $5(6)$ & - & $6(8)$ \\
\hline & Stem $>$ & $4(5)$ & $1(8)^{*}$ & - \\
\hline
\end{tabular}

${ }^{* * *} \mathrm{p}<0.01,{ }^{* *} \mathrm{p}<0.05,{ }^{*} \mathrm{p}<0.1$ 
Table S3: Differences among host tissues in fungal (top panel) and bacterial (bottom panel) endophyte richness in graminoids. Each cell in the table provides the number of times the tissue type on that row (the focal tissue) had higher richness than the tissue type in that column (the comparison tissue) followed by the number of studies reviewed for each comparison in parentheses. Significance was determined using a binomial sign test. For results from woody plants see Table S1, for results from forbs see Table $\mathrm{S} 2$

\begin{tabular}{|c|c|c|c|c|c|}
\hline \multicolumn{6}{|c|}{ Comparison tissue (Fungi) } \\
\hline & & Leaf & Root & Stem & \\
\hline \multirow{3}{*}{ 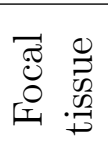 } & Leaf $>$ & - & $2(6)$ & $2(4)$ & \\
\hline & Root $>$ & $4(6)$ & - & $9(11)^{* *}$ & \\
\hline & Stem $>$ & $2(4)$ & $2(11)^{* *}$ & - & \\
\hline \multicolumn{6}{|c|}{ Comparison tissue (Bacteria) } \\
\hline & & & Leaf & Root & Stem \\
\hline \multirow{3}{*}{ 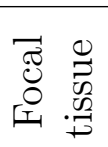 } & & Leaf $>$ & - & $1(6)$ & $1(6)$ \\
\hline & & Root $>$ & $5(6)$ & - & $9(9)^{* * *}$ \\
\hline & & Stem $>$ & $4(6)$ & $0(9) * * *$ & - \\
\hline
\end{tabular}


a)

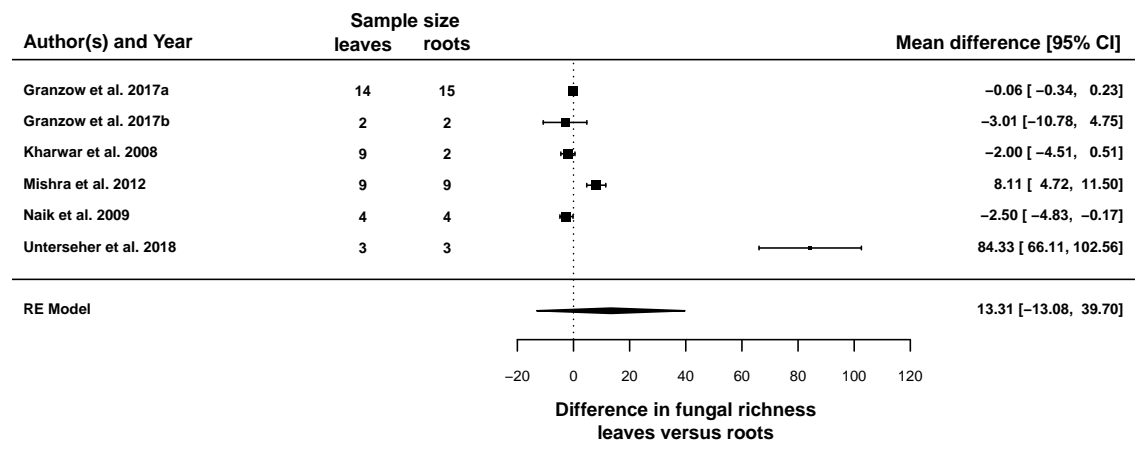

b)

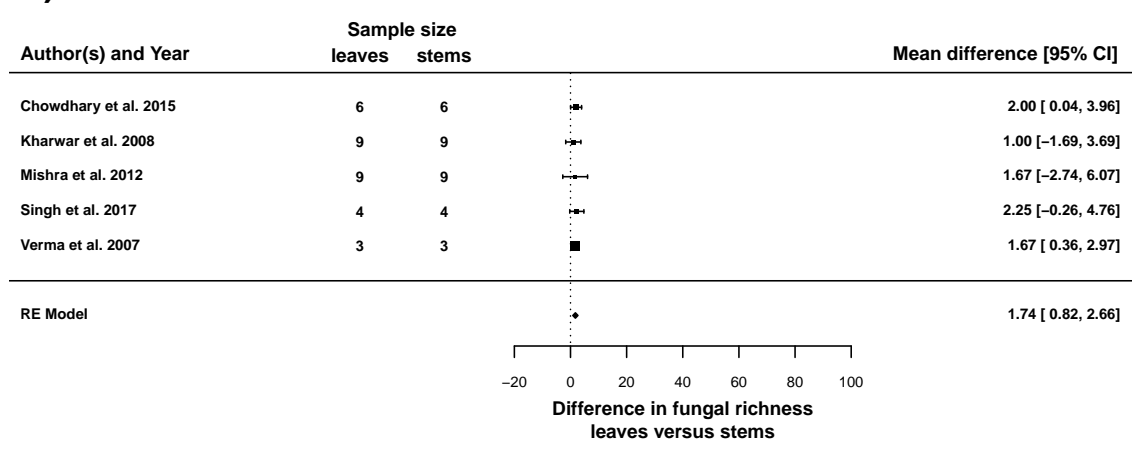

c)

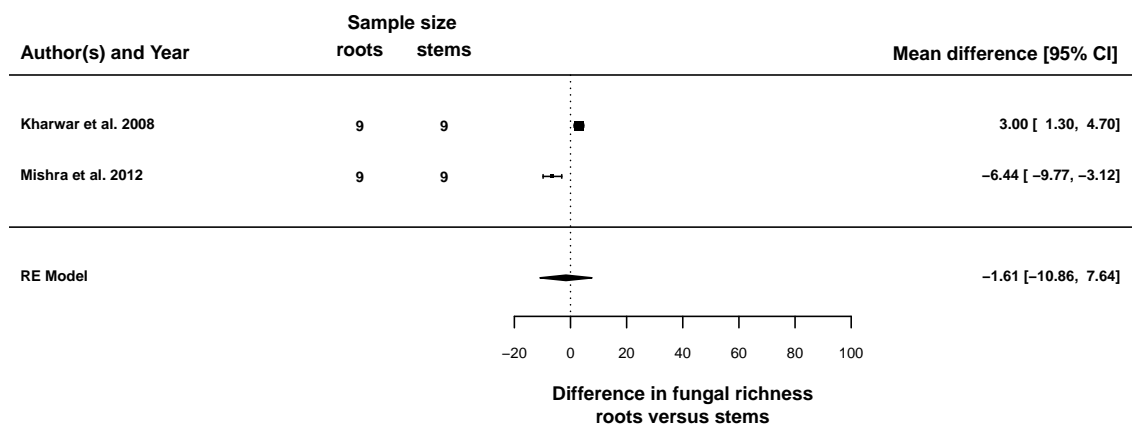

Figure S1: Differences in fungal endophyte richness among host tissues as determined through meta-analysis. Each panel depicts pairwise comparisons between two tissue types. Panel (a) depicts leaves versus roots, panel (b) leaves versus stems, and panel (c) roots versus stems. Mean differences between tissues for each study are shown in the right margins of each plot, with confidence intervals. No model was significantly supported at $p \leq 0.05$. Results were very similar for Shannon's diversity and can be seen in Fig. S2. Richness for Unterseher et al. (2018) was higher than the other studies because those authors relied on sequencing data whereas the other studies considered relied on culturing data. Two hosts were studied by Granzow et al. (2017) and results from each host are denoted by letters a and b. 
a)

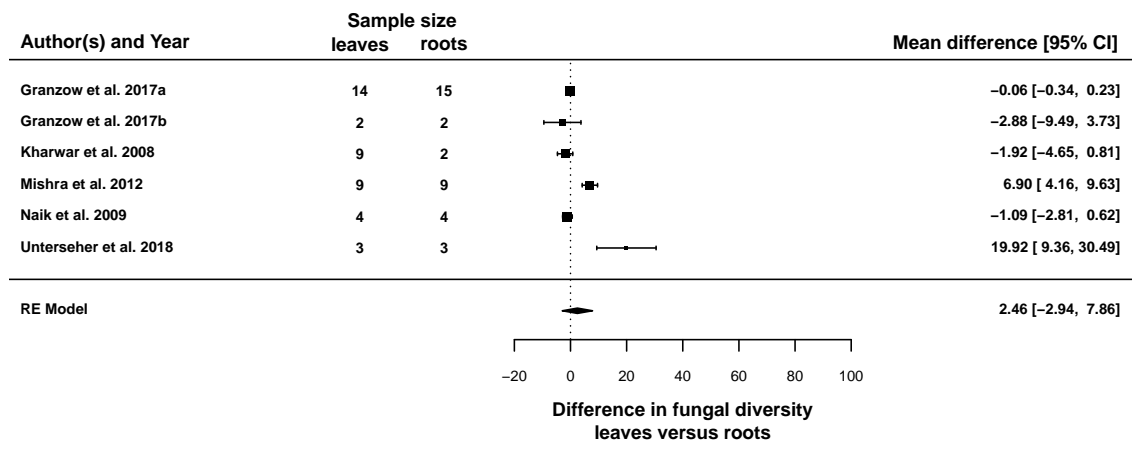

b)

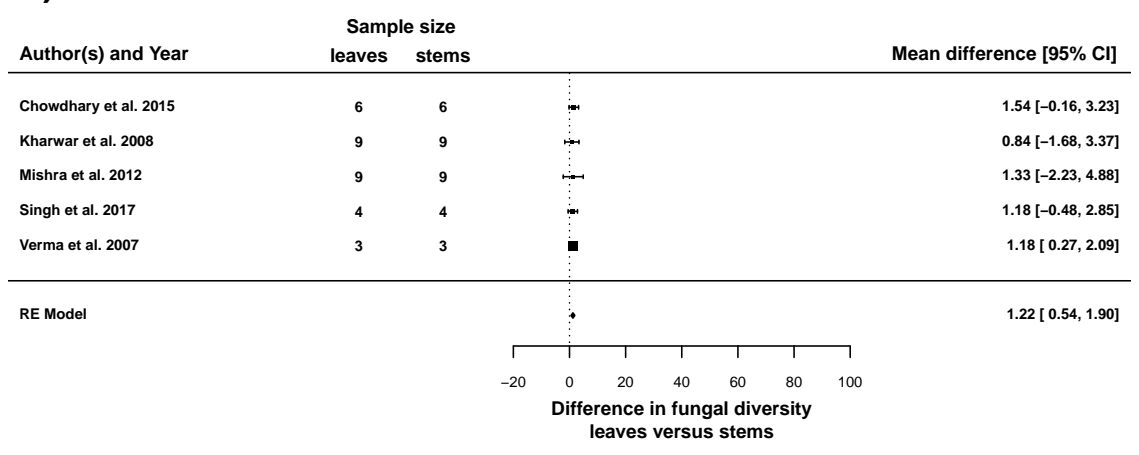

c)

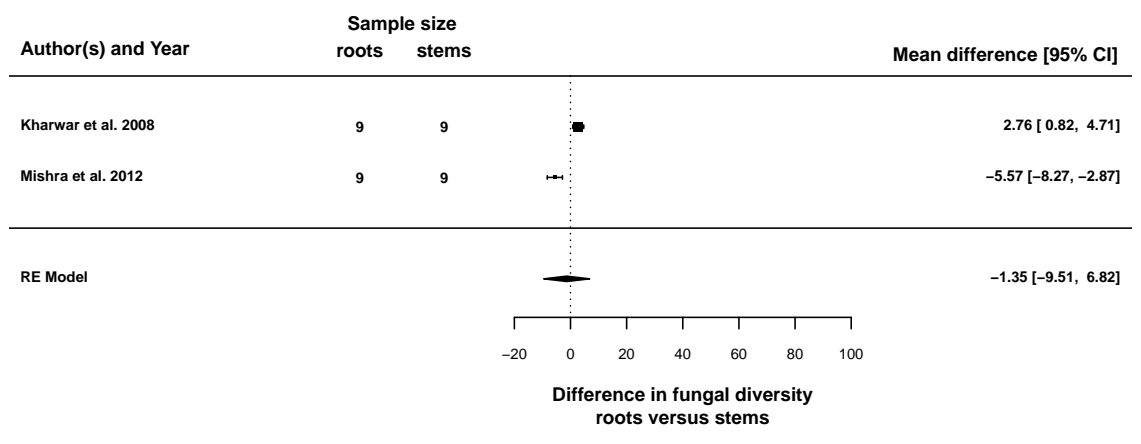

Figure S2: Differences in fungal endophyte diversity (exponentiated Shannon's entropy) among host tissues as determined through meta-analysis. Each panel depicts pairwise comparisons between two tissue types. Panel (a) depicts leaves versus roots, panel (b) leaves versus stems, and panel (c) roots versus stems. Mean differences between tissues for each study are shown in the right margins of each plot, with confidence intervals. Results were very similar for richness and can be seen in Fig. S1. Diversity for Unterseher et al. (2018) was higher than the other studies because those authors relied on sequencing data whereas the other studies considered relied on culturing data. Two hosts were studied by Granzow et al. (2017) and results from each host are denoted by letters a and $b$. 